\title{
Interférences
}

Ars scribendi

$9 \mid 2016$

Varia

\section{Modeler le prince ou critiquer le prince}

Claudien et Rutilius Namatianus, du panégyrique impérial au pamphlet politique

\section{Bruno Bureau}

\section{(2) OpenEdition}

1 Journals

Édition électronique

URL : http://journals.openedition.org/interferences/5743

DOI : 10.4000/interferences.5743

ISSN : $1777-5485$

Éditeur

HiSoMA - Histoire et sources des Mondes antiques

Référence électronique

Bruno Bureau, « Modeler le prince ou critiquer le prince », Interférences [En ligne], 9 | 2016, mis en ligne le 18 janvier 2018, consulté le 15 septembre 2020. URL : http://journals.openedition.org/interferences/ 5743 ; DOI : https://doi.org/10.4000/interferences.5743

Ce document a été généré automatiquement le 15 septembre 2020

Tous droits réservés 


\section{Modeler le prince ou critiquer le prince}

Claudien et Rutilius Namatianus, du panégyrique impérial au pamphlet politique* $^{*}$

Bruno Bureau

\section{Introduction}

1 La question de l'évolution de la nature et de la perception du pouvoir impérial à l'époque des successeurs de Théodose est rendue extrêmement complexe par deux éléments conjoints et difficilement séparables : d'un côté elle implique des événements et leur relecture idéologique (les faits et leur mise en forme), de l'autre elle fait appel, de manière implicite ou explicite, à des notions traditionnellement liées à la figure impériale et à la présence plus ou moins discrète du christianisme. Celui-ci est la religion des princes, mais son caractère de religion d'État, au sens moderne du terme, est loin d'être aussi simple qu'il pourrait y paraître à première vue ${ }^{1}$.

Dans ce contexte, les œuvres littéraires qui nous sont parvenues et qui traitent de ces questions en Occident le font clairement à travers un filtre qui constitue à la fois un biais pour la reconstruction des faits et un éclairage sur leur réception. Le panégyriste Claudien pourrait être considéré comme le canal de transmission du discours officiel sur l'Empire et sa politique. Mais de nombreuses études récentes ont montré que rien dans l'expression « discours officiel sur l'Empire et sa politique » n'est à prendre sans nuance ${ }^{2}$. D'où émane ce que l'on tient pour le « discours officiel »? Le panégyriste est-il simplement la caisse de résonance, le porte-parole des politiques qui, par lui, se justifient a posteriori? Ou bien a-t-il une autre fonction, celle de bâtisseur d'opinion, en construisant un discours proposé aux sujets sur leur prince et ce qu'il doit accomplir? Tout porte à croire qu'il assume clairement les deux, mais, si le fait est assuré, il est souvent délicat de voir dans quelle partie (justificative ou exhortative) ranger les éléments des discours. Rutilius Namatianus s'impose alors comme contrepoint exact de Claudien, mais là encore son statut est aussi brouillé que celui du panégyriste. Certes 
Claudien et Rutilius s'opposent par exemple sur la figure de Stilicon (héros romain parfait pour Claudien, traître pour Rutilius) et sur celle du prince (véritable monarque régnant et agissant pour Claudien, figure fantomatique pour Rutilius). Mais en même temps ils se rejoignent dans leur appartenance religieuse (tous deux sont attachés à la religion traditionnelle de Rome, même si Rutilius est bien plus virulent contre les chrétiens que Claudien qui s'adresse généralement à eux), dans leur proximité des cercles du pouvoir (Rutilius a été préfet de la Ville et Claudien, certes simple notaire, a été proche de Stilicon, donc d'Honorius), et surtout dans leur attachement à Rome, même s'il faut se demander s'ils mettent bien la même signification sous ce terme.

Or, dans la représentation des princes, Rome et sa figure ${ }^{3}$ sont précisément le lieu où peuvent se focaliser et donc s'appréhender au mieux les tensions complexes qui animent la période et qui écartèlent, en un sens que nous verrons, la figure princière. Celle-ci se trouve prise entre deux modèles (au moins, mais qui se combinent avec de nombreuses nuances) qu'il est particulièrement difficile, voire impossible, même pour un poète aussi doué que Claudien, de faire cohabiter sans failles. Or ce sont précisément ces failles que l'on retrouve dans les propos souvent amers de Rutilius, exposées dans le cadre semi-privé de l'itinerarium ${ }^{4}$.

L'idée d'une perte d'influence de Rome quand elle cesse d'être résidence impériale, et qui est probablement une réalité pendant la plus grande partie $\mathrm{du} \mathrm{IV}^{\mathrm{e}}$ siècle, mérite d'être reconsidérée pour la période qui nous intéresse (395-417) car, depuis Théodose en 389 , les empereurs viennent plus souvent à Rome et y résident parfois ${ }^{5}$. Ainsi Honorius se rend à six reprises dans la Ville, notamment pour un long séjour d'octobre 403 à juillet 404, qui sera l'occasion du panégyrique pour son sixième consulat par Claudien. Un autre séjour long a lieu entre novembre 407 et mars $408^{6}$, mais Claudien est probablement mort à ce moment-là̀. On peut certes expliquer ce regain d'intérêt pour la capitale traditionnelle par des circonstances particulières au règne $\mathrm{d}$ 'Honorius, voire par une politique particulière de ce prince ou de ses conseillers. Cela représenterait d'ailleurs une inflexion intéressante de la politique impériale à l'égard de Rome de la part de Théodose et de son successeur. Mais le fait que Valentinien III, successeur d'Honorius, prolonge cette pratique des séjours à Rome signifie sans nul doute autre chose ${ }^{8}$, une transformation de la nature et de la fonction de l'empereur, transformation qui affecte d'ailleurs, mais, nous le verrons, de façon différente, l'Orient et l'Occident, et peut même contribuer à affirmer deux modes distincts, voire concurrents, d'exercer le pouvoir impérial, selon que l'on se trouve dans la pars occidentalis ou dans la partie byzantine.

5 Notre propos ici sera de montrer comment les panégyriques de Claudien, entre 395 et 404, utilisent les rapports du prince avec la Ville et ses traditions à la fois sociales, culturelles et politiques (et en particulier le séjour impérial à Rome) pour construire une certaine image du pouvoir d'Honorius. Celui-ci s'affirme en effet de plus en plus comme un pouvoir occidental et romain avant que, de manière très claire, le poème de Rutilius ne vienne souligner l'échec de cette tentative ${ }^{9}$ et pointer l'abîme qui existe désormais à ses yeux entre la Ville - et la romanité qu'elle représente - et la figure princière ${ }^{10}$. Plus largement, il nous semble qu'à travers cette lecture en vis-à-vis des deux auteurs on peut mettre en évidence autour du même prince (Honorius) des éléments très complexes de résistance comme d'adhésion, partielles dans les deux cas, à une politique post-théodosienne qui tranche assez ouvertement sur les règnes 
précédents et paraît chercher une ou plusieurs nouvelles voies pour affronter les difficultés du pouvoir romain dans ces années troublées ${ }^{11}$.

Pour approcher au plus près l'image des liens entre la Ville et le pouvoir dans les textes, il faut garder en mémoire deux éléments qui guideront méthodologiquement notre enquête dans les pages qui vont suivre: les conceptions du pouvoir impérial que l'Antiquité tardive a pu hériter du principat, et la conception de l'Histoire qui permet aux Romains de penser le destin de leur État en lien avec la Ville qui l'a vu naître.

7 Pour ce qui concerne la représentation même du pouvoir impérial tel qu'il a pu être reçu du principat, on a montré avec raison que la figure princière pouvait se lire de deux manières qui se composent sans s'opposer ${ }^{12}$. D'un côté, le prince se définit par les pouvoirs qui lui sont légalement conférés et qui fixent son périmètre d'action, tout en le limitant théoriquement ${ }^{13}$, bien qu'en pratique la limitation soit aisément contournée. D'un autre côté, le prince se définit par tout un système d'autoreprésentation qui ne cesse de l'isoler du reste de la cité, de souligner son caractère particulier - à part et incomparable -, poussant alors le régime vers un modèle monarchique. On a ainsi opposé le principat où le premier élément l'emportait encore (au moins dans la représentation que le prince donne de lui-même ${ }^{14}$ ) au dominat dans lequel c'est le second élément qui prévaut, mais l'un des enjeux de la présente réflexion sera précisément de montrer que s'applique pleinement à la période que nous étudions ces mots d'A. Wallace-Hadrill : «the ambivalence itself may be of the essence [of Roman imperial power $]^{15}$. Thus the imperial Rome has a twin centre, part republican and part autocratic.»

Dans la perception que les Romains ont de leur propre histoire et donc de leurs traditions, il existe également, comme l'a montré $\mathrm{H}$. Inglebert ${ }^{16}$, des nuances qu'il résume en trois conceptions de l'Histoire : une conception centrée sur la Ville comme point d'origine et centre de la tradition romaine (conception urbocentrique) qui est « la présentation traditionnelle de l'histoire romaine, telle qu'on peut la trouver dans TiteLive $^{17}$ »; une deuxième conception (conception orbicentrique) qui « est celle qui entend par Romains les habitants de l'Empire ${ }^{18} »$; mais également une sorte de conception médiane (conception latinocentrique) qu'H. Inglebert définit comme le «fruit de la romanisation politique et de la latinisation culturelle, étroitement liées en Occident. Le point de vue latinocentrique allie à la fois des éléments culturels urbocentriques, ceux d'une Ville dont l'histoire est exceptionnelle depuis les origines, et des éléments politiques orbicentriques, ceux d'une citoyenneté devenue commune ${ }^{19}$ ».

Or il apparaît que ces trois catégories permettent, si on les applique aux discours de Claudien et de Rutilius, de mieux saisir les points de vue qui sous-tendent leur propos sur le pouvoir et qui peuvent dépendre des circonstances, du public et du lieu où le discours est donné. Car, comme le note encore H. Inglebert, « ces trois conceptions de la romanité, urbocentrique, orbicentrique, et latinocentrique, sont romaines. Durant l'Antiquité tardive, ces points de vue coexistaient, véhiculés par la propagande impériale ou les traditions scolaires ${ }^{20}$. » Et cela le conduit à cette conclusion dont nous espérons montrer combien elle permet de comprendre les ambiguïtés du discours de nos deux auteurs: "En définitive, dans le champ de l'historiographie tardo-antique, l'opposition entre urbocentrisme, ou latinocentrisme, et orbicentrisme, donc entre Latins et Grecs, a été culturellement plus importante que celle entre païens et chrétiens. L'essentiel était la définition de Rome, conçue comme la Ville, la culture latine, ou la citoyenneté impériale. Les païens d'Occident furent convertis par une 
histoire chrétienne latine de Rome et les païens d'Orient, par une présentation grecque christianisée de l'histoire de Rome ${ }^{21}$.»

Car, et c'est le dernier point méthodologique qu'il nous semble important de préciser avant d'aborder les textes, il existe évidemment, dans les réflexions sur le pouvoir romain, une prise de position implicite à propos du christianisme chez les princes et dans l'État, bien que ni Claudien ni Rutilius ne fassent la moindre allusion à une christianisation de la forme impériale du pouvoir, qui pour eux reste pensé dans les catégories de la religion traditionnelle. Le fait même qu'aucune imagerie chrétienne ne surgisse chez Claudien pour un prince évidemment chrétien pose le problème de l'attitude du panégyriste comme du poète du De reditu suo vis-à-vis non de la religion du prince, mais de la part que cette religion peut prendre concrètement dans l'exercice du pouvoir impérial ${ }^{22}$.

11 Nous articulerons donc notre propos en trois étapes successives. Une première étape consistera à analyser les contre-modèles offerts au prince et à en évaluer la portée à la fois idéologique et pragmatique. Nous pourrons alors mieux comprendre les lignes de force du modèle de l'empereur romain, tel qu'il est dessiné en particulier par Claudien, qui se construit à la fois en lien avec la tradition culturelle romaine et sous la pression des circonstances qui conduisent à (ré)activer tel ou tel élément idéologique. Enfin, en lisant un peu plus «en creux» ce qui se dissimule derrière les non-dits de Claudien et les «constats » de Rutilius, nous verrons comment ces éléments d'un modèle impérial dessinent en réalité un nouveau statut de la Ville et un nouveau rapport du prince d'Occident avec sa capitale historique.

\section{Basileus ou princeps, Orient ou Occident, deux modèles du prince?}

\section{Théodose dans le Panégyrique sur le quatrième consulat d'Honorius et le souvenir du panégyrique de 389 : l'Orient corrupteur}

Dans le discours que Théodose tient à Honorius dans le panégyrique de Claudien pour son quatrième consulat, l'empereur défunt, dans un retour en arrière sur une période antérieure à 395, avertit son fils en ces termes (4 Honor. 305-311) :

Inquinat egregios adiuncta superbia mores.

Non tibi tradidimus dociles seruire Sabaeos,

Armeniae dominum non te praefecimus orae,

Nec damus Assyriam, tenuit quam femina, gentem.

Romani, qui cuncta diu rexere, regendi,

Qui nec Tarquinii fastus nec iura tulere

Caesaris.

«L'orgueil, quand il vient s'y ajouter, souille les caractères remarquables. Pour toi, ce ne sont pas les dociles Sabéens que nous avons remis en ton pouvoir, nous ne t'avons pas mis comme un maître à la tête des contrées de l'Arménie, nous ne t'avons pas donné la race des Assyriens que tint en son pouvoir une femme. Ce sont les Romains qui ont longtemps tout gouverné que tu dois gouverner, ces gens qui n'ont supporté ni la morgue de Tarquin ni les lois que leur imposait César ${ }^{23}$. »

Dans ce texte écrit en 397, donc au moment où les tensions sont les plus vives entre l'Orient et l'Occident ${ }^{24}$, deux modèles semblent clairement s'opposer. D'un côté, selon un topos largement diffusé en Occident, un dominat convient parfaitement aux 
orientaux par nature portés à l'esclavage et qui, dans leur histoire, n'ont connu que des gouvernements tyranniques qu'ils ont acceptés, même s'ils pouvaient sembler faibles ${ }^{25}$. De l'autre côté, le peuple romain, peuple souverain aux deux sens du terme et dont l'histoire a montré qu'il résistait à toute tentative d'exercice tyrannique du pouvoir, nécessite un modèle impérial autre, qui s'éloigne de l'arbitraire tyrannique.

Sur le plan de la tradition politique qu'il véhicule et des pratiques ou réalités dont il se fait l'écho, ce texte appelle plusieurs remarques.

Il existe clairement un lien entre ce discours et le panégyrique que Pacatus avait composé pour Théodose en 389, ce qui induit une forme complexe, mais réelle, de continuité politique. Claudien semble avoir ici en tête une remarque de Pacatus incidente en apparence, mais très importante pour notre propos (Pacatus, Theod. 13, 2) :

Et quia uel longo orientis usu uel multorum retro principum remissione tantus quosdam luxus infecerat ut adulta consuetudo lasciuiae hautquaquam facile uideretur obtemperatura medicinae, ne quis se pati iniuriam putaret, a te uoluisti incipere censuram et impendia palatina minuendo nec solum abundantem reiciendo sumptum, sed uix necessarium usurpando dimensum, quod natura difficillimum est, emendasti uolentes.

«Et, parce que, soit en raison d'une longue fréquentation de l'Orient, soit en raison du laisser-faire de beaucoup de princes précédents, un si grand goût du luxe s'était emparé de certains qu'il ne semblait plus qu'une habitude de débauche aussi invétérée allât céder facilement devant un remède, pour éviter que quelqu'un ne pense qu'il subissait une injustice, tu as voulu que la censure commençât par ta personne et en réduisant les dépenses du palais, sans te contenter de repousser les frais superflus mais en prenant à peine ce qui t'était nécessairement alloué, tu as, chose naturellement extrêmement difficile, corrigé de leur plein gré les autres. »

Bien que certains détails de ce texte demeurent obscurs ${ }^{26}$, la corrélation entre la vision de l'Orient comme pervertissant les individus qui y vivent dans le laisser-aller et la nécessaire reprise en mains par une morale romaine rejoint le discours que Théodose tient à son fils dans la fiction de Claudien, mais, en un sens, Claudien dépasse Pacatus, comme il ressort clairement du passage où le rhéteur de 389 citait Tarquin le Superbe et où l'on peut mesurer un important écart (Pacatus, Theod. 20, 5-6) :

Quod si per rerum naturam liceret ut ille Romanae libertatis adsertor, regii nominis Brutus osor, precariae redditus uitae saeculum tuum cerneret studiis uirtutis parsimoniae humanitatis imbutum ac refertum, nullum toto orbe terrarum superbiae libidinis crudelitatis exstare uestigium, iam te ipsum qua publice qua priuatim uideret priscorum duritia ducum, castitate pontificum, consulum moderatione, petitorum comitate uiuentem: mutaret profecto sententiam tanto post suam et, cum Romanam dignitatem ac libertatem probaret meliore in statu imperatore te esse quam consule se fuisse, necessario fateretur Tarquinium submoueri debuisse, non regnum.

«Et si la nature permettait que Brutus, le héros qui revendiqua la liberté de Rome, le contempteur du nom royal, revenu pour une vie temporaire, vît le temps de ton empire tout pénétré de zèle pour la vertu, pour l'économie, pour la philanthropie, et où il ne reste sur toute la terre nulle trace d'orgueil, de désirs pervers, de cruauté, et toi-même qui vis tant en privé qu'en public dans l'austérité des chefs d'autrefois, la pureté des pontifes d'alors, la modération des consuls et l'amabilité envers les solliciteurs, il changerait d'avis sans tarder après tant de temps et, comme il verrait bien que la dignité des Romains et leur liberté est mieux assurée sous ton empire que sous son consulat, il confesserait inévitablement qu'il fallait bien chasser Tarquin, mais non la royauté ${ }^{27}$. »

$16 \mathrm{Si}$, apparemment, le propos est à peu près le même, plus développé en prose que dans les vers, quelques nuances sont importantes. Claudien ajoute César à Tarquin, ce qui pose la question d'un regnum malum, autrement dit d'une mauvaise manière d'exercer 
les prérogatives impériales, qui relierait la superbia des mauvais princes à une époque royale honnie. De ce fait, en utilisant la forme verbale regendi, Claudien évite de qualifier ouvertement ici le pouvoir d'Honorius de regnum ${ }^{28}$. Il maintient ainsi une volontaire ambiguïté entretenue par le parfait rexere qui semble renvoyer à l'état révolu de la libera res publica à laquelle s'opposerait le gouvernement d'un seul, sans que ni le pouvoir ancien du sénat et du peuple, ni celui du prince ne soient explicitement désignés comme royaux. Le pouvoir impérial apparaît donc ici placé sur une ligne de crête étroite. Certes, il relève d'une forme de monarchie, mais cette monarchie ne doit pas oublier d'où elle vient et doit donc s'imposer des bornes morales qui rejoignent une lecture "constitutionnaliste» de la fonction. Celle-ci est clairement affirmée par Pacatus dans la mention de la censure pour Théodose ${ }^{29}$, mais elle est moralisée ${ }^{30}$ et couplée par Claudien avec la nécessaire adaptation du système d'autoreprésentation impériale. Le prince doit s'imposer à lui-même, en raison du peuple qu'il gouverne, de se conformer aux valeurs morales et politiques qui sont celles du peuple romain ${ }^{31}$. Que cet élément soit mis dans la bouche du père du prince, donc dans une figure qui a autorité sur lui, indique clairement que nous sommes ici en face d'un modelage de la figure princière selon des normes que Claudien et ses commanditaires, Stilicon et ses proches, forgent pour affirmer la singularité du jeune empereur, par exemple par rapport à son frère.

Car il est évident que cet élément n'est pas sans arrière-pensées politiques marquées par l'actualité des rapports exécrables entre les deux frères. Élevés en Orient dans une cour orientale, ils représenteraient tous deux, sans les sages conseils de Théodose, ces princes élevés dans le luxe et le goût de l'autocratie ${ }^{32}$. Qu'Honorius seul reçoive ici les conseils de son père souligne " en creux » que le modèle qui prévaut dans la nouvelle capitale orientale n'est sans doute pas celui-là.

\section{Honorius prince-enfant : un nécessaire compromis entre la fonction et l'action}

Or ce modelage est rendu possible par une autre donnée extrêmement importante ici, mais souvent négligée : nous sommes en présence d'un empereur-enfant ${ }^{33}$.

Avec le décès prématuré de Théodose, qui laisse en 395 un fils âgé de 11 ans seul héritier de l'Occident, la question des empereurs-enfants se pose effectivement en des termes qui n'avaient été établis que très rarement auparavant $t^{34}:$ il est alors clairement mis en évidence que le système de la proclamation d'enfants comme Augustes ne peut plus se penser en termes strictement dynastiques, mais pose désormais un véritable problème politique ${ }^{35}$. En effet, la présence d'un enfant sur le trône conduit nécessairement à repenser la fonction impériale et la place que l'empereur occupe dans le gouvernement de l'Empire lui-même. Mais selon quelles modalités? Si l'empereur se cantonne dans une fonction strictement représentative, autrement dit dans la fonction d'autoreprésentation, le problème est évidemment minoré et il est facile de trouver des justifications plus ou moins morales à l'enfance comme illustration de vertus " impériales ", ne serait-ce que dans le thème de l'empereur porphyrogénète. Or c'est précisément par ce thème, et la critique de certains usages que l'on en fait, que Théodose ouvre son discours (4 Honor. 214-220) :

Si tibi Parthorum solium Fortuna dedisset,

Care puer, terrisque procul uenerandus Eois 
Barbarus Arsacio consurgeret ore tiaras :

Sufficeret sublime genus luxuque fluentem

Deside nobilitas posset te sola tueri.

Altera Romanae longe rectoribus aulae

Condicio. uirtute decet, non sanguine niti.

«Si c'était le trône des Parthes que la Fortune t'avait donné, mon cher enfant, et si

c'était sur les lointaines terres de l'Europe que pour rendre hommage à une tiare sur un visage d'Arsacide un barbare se levait, une haute naissance suffirait et ta seule noblesse pourrait veiller sur toi qui coulerais sans rien faire une vie de luxe. Mais tout autre est la condition de la cour de Rome pour les gouvernants, il y faut s'appuyer sur la vertu, non sur le sang. "

Ce passage complète et éclaire le tableau précédent dans la logique d'un prince-enfant confronté à l'exercice du pouvoir. Encore faut-il bien en saisir tous les paramètres. Certes, le texte oppose la condition des despotes orientaux, rois fainéants qui règnent sans gouverner, parce qu'ils sont nés dans la pourpre et que la naissance leur suffit, et la pratique romaine fondée sur la vertu, mais on notera précisément que le poète ne dit rien de l'activité concrète du souverain romain, il ne parle ici que de ses vertus en général sans indiquer comment il exerce réellement son pouvoir.

Il se pose alors un double problème: l'opposition que présente Théodose est-elle si claire que Claudien semble le dire, et qu'attend-on concrètement de l'empereur d'Occident qui le sépare d'un potentat oriental?

La seconde question est sans doute la plus facile à résoudre. Le thème de la vertu du prince est très certainement réactivé ici parce qu'il s'agit d'un prince dont le jeune âge réduit concrètement la fonction à une représentation du pouvoir impérial, ce que M. McEvoy nomme, un peu trop rapidement nous allons le voir, l'infantilisation du pouvoir ${ }^{36}$. Nous reviendrons dans notre deuxième partie sur l'évolution de cette conception dans les panégyriques ultérieurs de Claudien et, dans la troisième, sur les conséquences de cette représentation princière. Il est clair, pour l'heure, que d'un enfant de 13 ans on n'attend rien d'autre que d'illustrer la fonction impériale, mais en sachant qu'il devra un jour gouverner. Les deux éléments ne sont nullement antithétiques et n'imposent pas l'image d'un prince qui régnera sans gouverner, même si, pendant quelques années, il doit le faire ${ }^{37}$.

La première question est bien plus complexe. Certes, Claudien semble ici condamner la manière orientale d'exercer le pouvoir, mais que penser alors de l'apparition du prince en dieu-soleil à la fin du même poème (4 Honor. 570-578) :

$$
\text { ... sic numina Memphis }
$$

In uulgus proferre solet; penetralibus exit

Effigies, breuis illa quidem : sed plurimus infra

Liniger imposito suspirat uecte sacerdos

Testatus sudore deum ; Nilotica sistris

Ripa sonat Phariosque modos Aegyptia ducit

Tibia ; summissis admugit cornibus Apis.

Omnis nobilitas, omnis tua sacra frequentat

Thybridis et Latii suboles;

"C'est ainsi que Memphis a coutume de faire paraître ses dieux aux yeux du peuple ; la statue sort des profondeurs du temple, et certes elle est petite, mais plus d'un prêtre vêtu de lin soupire sous le poids qu'on lui impose, attestant par sa sueur qu'il porte un dieu. La rive du Nil résonne des sistres et la flûte égyptienne conduit les modulations de Pharos ; les cornes baissées, Apis mugit. Toute la noblesse, toute la descendance du Tibre et du Latium se presse sur tes pas sacrés. » 
Si plusieurs éléments contribuent à réduire l'apparente contradiction, ils ne peuvent toutefois (et c'est là l'essentiel) la gommer totalement. On pourra dire tout d'abord qu'il s'agit d'une comparaison, et donc d'un discours que le poète met à distance et où il déploie les fastes de son érudition. Dans ce cadre, Honorius est beau comme un dieu, il n'est pas un dieu ${ }^{38}$, et le poète offre à son public un simple délassement exotique. Peutêtre, mais dans ce cas, cela implique qu'il ne faille pas prendre au sérieux cette image du prince, ce qui devient finalement contre-productif. On peut dire aussi que la cérémonie est une cérémonie aulique (nous sommes à Milan, résidence de la cour depuis le IV siècle, qui n'a évidemment pas la tradition historique, sociale et cultuelle de Rome), où le discours est prononcé devant des courtisans et une délégation du sénat, et non dans un cadre proprement civique, comme ce serait le cas à Rome, où le discours serait prononcé devant le sénat et le peuple romain. Cela peut encourager une insistance mise sur la représentation de la souveraineté, au détriment de l'image du prince-citoyen. Certes, mais l'auditoire n'en demeure pas moins essentiellement occidental, et ce tableau orientalisant reste étrange. Est-il bien habile de souligner ainsi devant des occidentaux que le jeune prince vient d'Orient ${ }^{39}$ ?

Quelque justification qu'on lui trouve (ludique ou sérieuse, rhétorique ou plus politique), cette comparaison, évidemment à la gloire du laudandus, laisse planer l'impression que le discours de Claudien oscille finalement entre deux conceptions sans apparemment trancher, et que si, d'un côté, Théodose présente à son fils une vision traditionnelle et romaine du pouvoir impérial, de l'autre le panégyriste n'hésite pas à faire droit à un cérémonial dont il souligne l'orientalisme. Cela est d'autant plus troublant que dans le panégyrique précédent (3 Honor.), composé pour le $1^{\mathrm{er}}$ janvier 396, on ne trouve rien de tel, alors que la comparaison y aurait été sans doute mieux venue, le prince ayant 11 ans et n'étant donc clairement capable que de la fonction de représentation. Au contraire, Claudien insiste (v. 78-87) sur la volonté de l'enfant d'aller guerroyer avec son père qui lui demande de rester veiller sur l'Empire tandis qu'il part combattre. Il nous semble donc possible de voir dans le Panégyrique sur le quatrième consulat d'Honorius une mise en scène complexe et partiellement ambiguë de la dualité constitutive de la fonction impériale. Toutefois, complexité et ambiguïté ne signifient nullement ici relativisme ou flou dans la vision impériale, mais bel et bien établissement d'une hiérarchie implicite entre les deux images princières en faveur de l'image occidentale et romaine ${ }^{40}$.

\section{Claudien et Synésius, princeps et basileus sont-ils les deux versants d'une même réalité ?}

Puisque le discours du poète n'est pas sans ambiguïtés aux moins apparentes, il faut définir le plus précisément possible la façon dont Claudien fait pencher la balance vers un pouvoir typiquement romain, autrement dit comment il entérine les éléments du cérémonial aulique tout en les dissociant d'un pouvoir tyrannique, despotique ou arbitraire. S'il est pourvu de toute la magnificence qui est due au maître du monde, l'empereur de Rome n'est pas le Grand-Roi ou un roi théocratique de l'Orient. Mais nous pouvons aller plus loin, en comparant le discours de Claudien/Théodose à Honorius et celui de Synésius à Arcadius ${ }^{41}$ : Honorius n'est pas le Grand-Roi, mais il n'est pas non plus le basileus de Constantinople. 
27 Avant d'aborder Synésius, on remarquera tout d'abord, à la suite d'autres, que les éléments qui lient orientalisme, cérémonial et exercice absolu du pouvoir sont absolument topiques et participent d'un discours qui relève, comme le montrent par exemple les références historiques de Claudien à Sémiramis, d'une représentation culturelle qui réactive le lieu commun du basileus oriental ${ }^{42}$, vivant dans le faste et l'oisiveté et établissant entre lui-même et ses sujets d'infranchissables barrières. Or c'est bien ce que Synésius présente à Arcadius un an plus tard, en $399^{43}$, comme le signe de la dégénérescence du pouvoir réel ${ }^{44}$. Le chapitre $14 \mathrm{du}$ De regno peut à cet égard constituer l'exact pendant, en milieu grec, du discours que le Théodose de Claudien adressait à son fils. Le développement mérite d'être cité dans son intégralité (Synésius, De regno 14) :

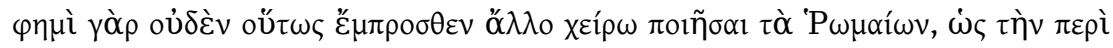

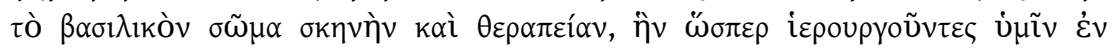

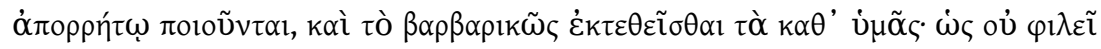

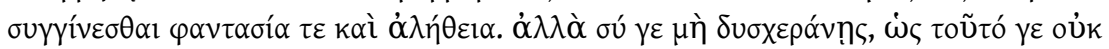

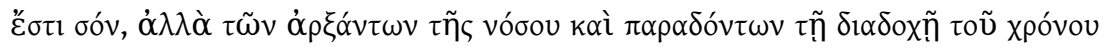

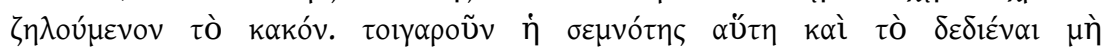

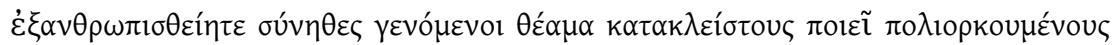

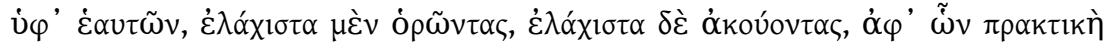

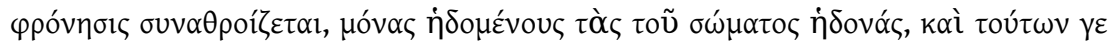

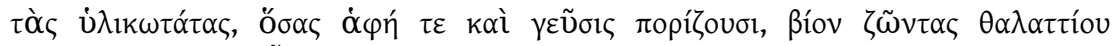

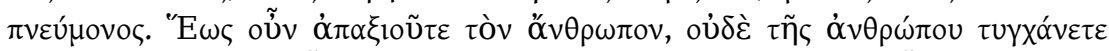

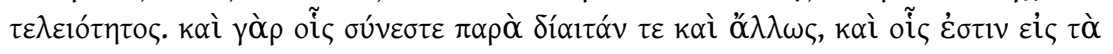

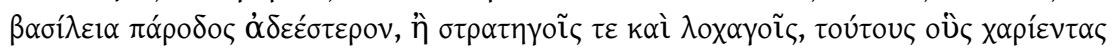

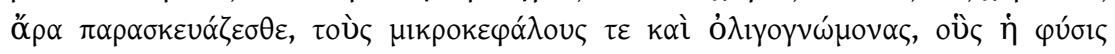

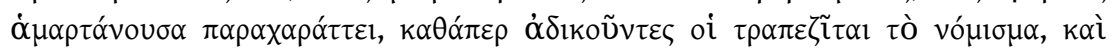

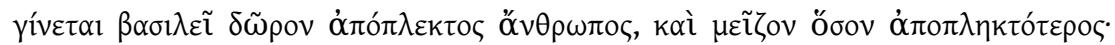

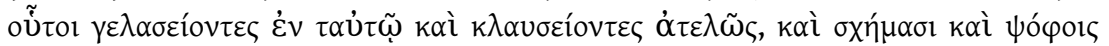

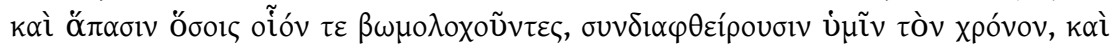

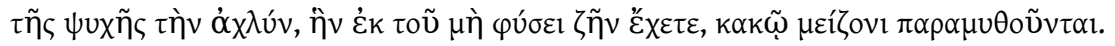

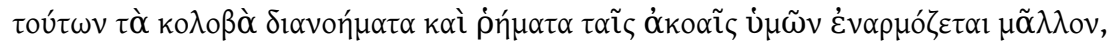

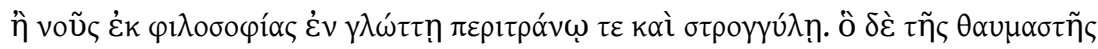

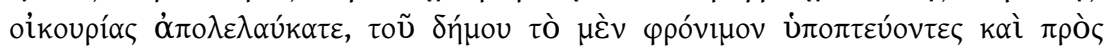

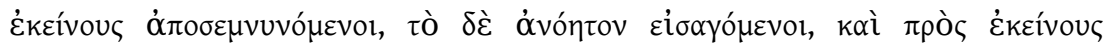

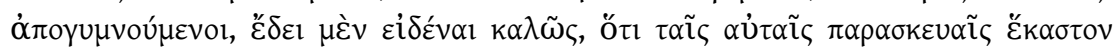

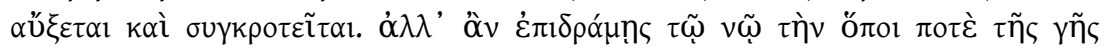

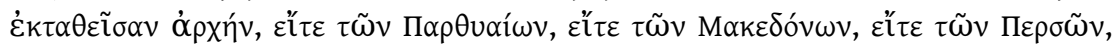

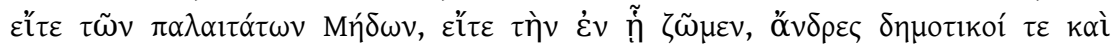

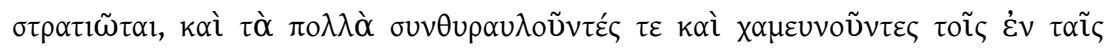

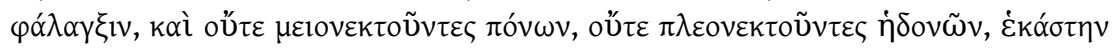

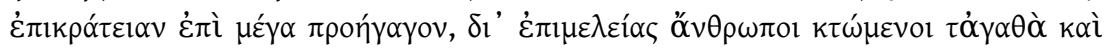

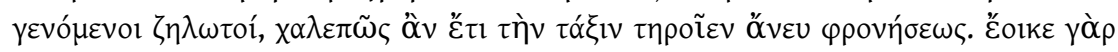

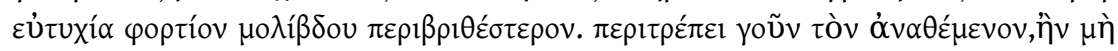

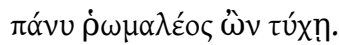

"J'affirme que rien jadis n'a été plus fatal à l'Empire que le luxe théâtral déployé autour de la personne du Prince. On prépare dans le mystère un faste pompeux, dont vous faites ensuite étalage à la manière des barbares. Mais l'ostentation cache la faiblesse sous des dehors trompeurs. Que mon langage ne te blesse point ; la faute n'est pas à toi, mais à ceux qui, les premiers, introduisirent ces habitudes pernicieuses et les transmirent à leurs successeurs. Le mal n'a fait que s'accroître avec le temps. Votre majesté même et la crainte qu'en vous laissant voir souvent vous ne soyez l'objet de moins de respect vous retiennent enfermés dans vos palais. Là, devenus vos propres captifs, privés de voir et d'entendre, vous perdez les leçons 
pratiques de l'expérience; vous ne vivez plus que pour les plaisirs du corps, et pour les plus grossiers d'entre ces plaisirs, ceux du goût et du toucher; votre existence est celle d'un polype. Ainsi, pour vouloir être plus que des hommes, vous tombez même au-dessous de l'homme. Tandis que vous ne laissez pas pénétrer jusqu'à vous les centurions et les généraux, pour vous égayer vous faites votre société habituelle d'êtres à tête petite, à intelligence bornée, vrais avortons, produits imparfaits de la nature, semblables à de la fausse monnaie. Un fou devient un don digne d'être offert à un roi, et plus il est fou plus ce don est précieux. Incertains entre la joie et le chagrin, ils pleurent et rient tout à la fois; leurs gestes, leurs cris, leurs bouffonneries de toute espèce vous aident à perdre le temps. L'esprit aveuglé pour n'avoir pas vécu conformément à la nature, vous cherchez un remède encore pire que le mal; de sottes idées, de ridicules propos vont mieux à vos oreilles que les sages pensées sorties de la bouche éloquente d'un philosophe. L'unique avantage de cette existence clôturée, le voici : c'est que, si un citoyen se distingue par son intelligence, vous vous défiez de lui, vous ne vous laissez voir qu'à grand'peine; mais un insensé, au contraire, vous le faites venir, vous vous révélez entièrement à ses yeux. Il ne faut pas l'oublier cependant, les mêmes moyens par lesquels un État s'est formé servent à l'agrandir. Parcours toute la terre par la pensée; vois les empires des Parthes, des Macédoniens, des Perses, des anciens Mèdes, vois le nôtre : toujours tu trouveras que les États n'ont dû leur grandeur qu'à des guerriers, chers à leurs compagnons d'armes, partageant avec eux la rude vie des camps, couchant comme eux sur la dure, se soumettant aux mêmes fatigues, ne s'accordant que les mêmes plaisirs. C'est par leurs travaux qu'ils élevaient si haut leur fortune; et une fois au faîte de la puissance, ils ne s'y maintenaient que par la sagesse de leurs conseils; car la prospérité est comme un fardeau plus lourd que le plomb, on ne peut la supporter sans en être accablé, à moins d'avoir une âme forte. »

La parenté entre les deux textes est telle que l'on pourrait presque penser que l'un, le grec, répond à l'autre. Si tel n'est pas le cas, leur mise en vis-à-vis apporte plusieurs enseignements. La reconfiguration du prince selon un modèle qui s'écarterait du despotisme oriental est un élément commun à l'Orient et à l'Occident et participe donc d'une tendance idéologique "romanisante », très probablement issue de l'entourage de Théodose. Elle montre, avec le décalage dû à l'âge d'Arcadius, que le modèle du prince fainéant est condamné au profit d'un exercice actif du pouvoir. Nous sommes donc bien en présence d'une forme de débat politique réel sur l'exercice du pouvoir princier, dont l'enjeu paraît clairement se focaliser autour de la notion de semnôtès, la majesté du prince, qui, dans le discours de Synésius, est paradoxalement amoindrie par le tropplein de faste et d'honneur dont on entoure l'empereur.

Or on a remarqué que ce mot grec, à connotation nettement positive, n'avait pas d'équivalent latin, car ni maiestas ni dignitas ni grauitas n'en recoupent exactement le sens ${ }^{45}$, qui pourrait se rattacher davantage à la qualité d'augustus, dont on notera qu'il n'existe pas en latin de substantif abstrait dérivé. Quoi qu'il en soit, chez l'hellénophone qu'est Claudien, il semblerait que ce soit maiestas qui renvoie à cette notion, comme en témoignent les deux emplois dans le Panégyrique sur le quatrième consulat d'Honorius (v. 122 et 519) qui montrent une intéressante évolution. Si le premier est en effet relié au thème de la porphyrogénèse ${ }^{46}$, le second, de manière très habile, inclut dans la maiestas autre chose que la simple représentation du pouvoir, l'exercice d'une autorité réelle. Il semble bien rejoindre la véritable semnôtès selon Synésius, le respect qu'inspire non le luxe de son palais et de sa cour mais le pouvoir vertueux et noble du prince (4 Honor. 516-520) :

... responsa uerentur

Legati, grauibusque latet sub moribus aetas.

Quantus in ore pater radiat! quam torua uoluptas 
Frontis et augusti maiestas grata pudoris!

Iam patrias imples galeas;

«les ambassadeurs accueillent avec déférence tes réponses et ton jeune âge disparaît sous la gravité de ton caractère. Comme ton père brille sur tes traits! Quelle autorité sous le charme de ton front, que d'agrément dans ta majesté pleine d'auguste pudeur! Déjà ta tête peut porter le casque de ton père. »

30 au cérémonial ou au paraître du prince, voire à sa naissance, mais à ses qualités propres qui en font un puer senex, qui déjà assume (au moins fictivement) ce que sera son regnum, la réalisation exacte du programme de gouvernement fixé par Théodose, celui qui unit exploits guerriers et rigueur morale ${ }^{47}$. Ainsi se trouve parfaitement résumée la juxtaposition des deux modèles : l'empereur ne sera semnos que parce qu'il unit en lui à des qualités de naissance qui le placent au-dessus de la commune humanité des vertus morales, militaires et politiques qu'il sait exercer.

sommes donc ici, début 398 chez Claudien et en 399 chez Synésius, en présence d'une parfaite illustration de la tension qui préside à la représentation de la figure impériale, du double modèle qu'elle convoque. Le prince se distingue certes de tous les autres mortels, mais non pas tant par son pouvoir ou son faste que par son excellence morale et politique. Il n'est pas plus que les autres, il est mieux. Or, concernant Honorius, deux aspects peuvent à ce point nous retenir : la tension qui existe chez un prince-enfant entre ce qu'il est et ce qu'il devient, et la question de la diffusion de ce modèle de manière identique en Occident et en Orient.

Si le prince est encore, selon des critères strictement romains, un gouvernant en devenir, et si son empire est (pour quelques années encore) une fonction plus qu'un réel pouvoir, on comprend qu'il faille guider ce devenir du prince à travers la figure de Théodose, et la tension entre les deux pôles (ce qu'est aujourd'hui objectivement le prince, un adolescent de 13 ans, et ce qu'il sera un jour) s'explique aisément. Mais de cette tension même on peut clairement déduire que le modelage de la figure princière fluctue selon des critères qui visent finalement à imposer une double image du prince, comme détenteur incontesté de la fonction impériale (versant que nous définirions comme aulique et monarchique) $)^{48}$, et comme empereur en devenir pour se conformer à l'idéal de l'optimus princeps (versant civique). Cela nous conduit, à la suite d'autres chercheurs, à considérer qu'il existe bien, en Occident, deux conceptions superposées de la fonction impériale qui se réactivent alternativement ou conjointement, selon des modalités dont on peut tracer l'histoire dans les origines mêmes de cette forme de gouvernement ${ }^{49}$. Mais on soulignera ici qu'il s'agit non pas d'un élément de rupture qui séparerait principat et dominat, mais d'une profonde continuité qui explique que le discours du prince-roi et celui du prince-citoyen puissent cohabiter, à l'intérieur de limites que nous aident à cerner les critiques de la tyrannie présentes dans le panégyrique de 398.

Or cette vision paraît bien une vision commune à une certaine partie de l'entourage du prince, que ce soit en Orient ou en Occident, puisque l'on retrouve, tenu à Arcadius par Synésius, un discours fort proche. Ici se pose clairement, en cette année où les rapports entre les frères sont au plus mal, la question de l'unicité de la représentation impériale. À lire conjointement Claudien et Synésius, on pourrait être tenté de rejoindre totalement la conclusion de M. McEvoy: "Child-emperor rule in the West did not develop independently of the East, and nor should developments in western imperial ceremonial and presentation be seen as divorced from Constantinopolitan 
developments. These developments were, rather, part of an overarching and common developing imperial culture, and should be viewed as $\operatorname{such}^{50}$ », et considérer que les proximités entre Claudien et Synésius traduisent clairement une "pensée unique » de l'Empire, confronté à des princes qui ne peuvent réellement gouverner (Honorius) ou qui ne s'intéressent pas au gouvernement (Arcadius). Mais les choses ne sont pas si simples, car la tension entre semnôtès du monarque et action du uir ciuilis dégage certainement deux tendances dans la manière même de concevoir le pouvoir impérial, deux philosophies concomitantes et sans doute parfois concurrentes du pouvoir. Il est d'ailleurs probable, pour ne pas dire avéré, que, dans les nombreuses coteries qui peuplaient les cours, certaines aient pu prendre parti pour l'une ou l'autre des conceptions, en fonction soit de convictions personnelles, soit d'intérêts propres, et que, loin de l'unanimité qu'idéalise le panégyrique, il y ait eu, autour d'un prince jeune et encore influençable, un véritable «bouillonnement » politique.

Mais s'en tenir là serait masquer une différence fondamentale entre le discours de Claudien et celui de Synésius. Pour ce dernier, Arcadius est soumis à une tentation domestique qui est liée, non pas au fait qu'il soit en Orient, mais à l'adulation et au

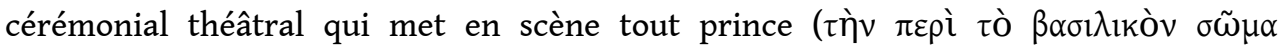

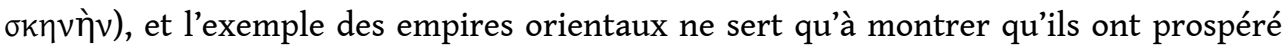
quand ils ont eu à leur tête de vaillants guerriers. Chez Claudien au contraire, par-delà l'unité idéologique de façade sur ce qu'est un bon prince, l'Orient est clairement, comme chez Pacatus, désigné comme corrupteur et comme opposé à l'exercice romain du pouvoir. Là où Synésius propose à Arcadius, outre des conseils d'actualité qui ne nous occupent pas ici, une sorte de philosophie du parfait basileus, autrement dit un miroir du monarque parfait, Claudien offre à la contemplation et à l'imitation du jeune Honorius ce qui constitue le modèle parfait de l'empereur romain, le parfait princeps populi Romanisi.

\section{Exercice romain du pouvoir et exercice du pouvoir à Rome}

Avant d'aborder la question de la représentation par Claudien de l'optimus princeps, à la fois comme ciuis vertueux et proche de ses ciues, et comme attentif à respecter les formes traditionnelles de l'exercice romain du pouvoir, il convient de se souvenir de la question que posait très justement A. Wallace-Hadrill : « why should certain modes of behaviour, notably respect for the senate, continue to be regarded as the true tradition, if there were not further factors that made it convenient to do $\mathrm{so}^{52}$ ? » et de ne jamais perdre de vue deux évidences: si Claudien utilise le thème de l'empereur ciuis et du princeps sur le modèle des princes flaviens ou antonins, c'est d'abord que ce modèle a encore un sens politique pour les auditeurs, ou au moins une partie d'entre eux ${ }^{53}$, et qu'il n'est donc pas une fiction littéraire mais un moyen de favoriser leur allégeance au pouvoir ${ }^{54}$, et ensuite que l'entourage du prince et les auditeurs ont intérêt à voir perdurer ce modèle ou à le restaurer. C'est dans ce contexte qu'il faut comprendre la relation étroite que Théodose puis Honorius nouent avec la ville de Rome et que nos textes font apparaître sous trois modalités complémentaires. Le lien du pouvoir impérial à la Ville d'où il tire son origine et où il peut s'exprimer dans toute sa spécificité impose, pour être réellement activé comme outil de gouvernement, une certaine manière de se comporter à Rome. Ce comportement du prince fondé sur la 
morale et la tradition romaines vise clairement à resserrer le lien entre le prince et la Ville, en tant que ce lien construit l'identité impériale de l'Occident. Mais cette romanité de plus en plus affirmée par l'Honorius des panégyriques de Claudien, et que l'on pourrait prendre pour "argent comptant", voit dans le poème de Rutilius une confirmation paradoxale dans ce qui équivaut clairement à un retournement de perspective : c'est la Ville, son histoire, sa culture, son mode de vie, qui définissent la romanité et l'appartenance à la communauté romaine, et la présence ou l'absence du prince (de ce prince-là) dans la Ville ne change rien à cet état de fait.

\section{Le prince à Rome, retour aux origines et calcul politique}

Dans le contexte d'une reconfiguration de la figure du prince, qui serait conforme à la tradition romaine de l'optimus princeps, la venue du prince à Rome en 404 joue évidemment un rôle essentiel et marque l'aboutissement dans un acte politique fort des conseils donnés naguère par Théodose. L'adventus romain incarne (au moins dans l'esprit du panégyriste) l'avènement d'un prince qui n'est plus ni un puer, ni un adulescens, mais un adulte qui assume désormais la totalité de sa charge.

Or cet adventus de 404 joue à notre sens, dans cette reconfiguration amorcée pour Honorius dans le panégyrique pour son quatrième consulat, un rôle d'autant plus déterminant qu'il succède à deux adventus fameux, celui de Constance II en 357 et celui de Théodose en 389. Si l'on veut comprendre la représentation que Claudien construit des rapports du prince avec Rome, il faut considérer ces trois adventus sur deux plans indissociablement imbriqués, d'une part celui de la relation idéologique, politique, sociale et religieuse que ces venues tissent entre le prince et Rome, et d'autre part celui de la mise en scène littéraire qui éclaire l'un ou l'autre aspect du cérémonial et déplace ainsi le projecteur vers l'un ou l'autre aspect de la fonction impériale.

Le premier élément commun à ces trois venues est le lien entre adventus et triomphe, l' adventus prenant la place du triomphe dans le contexte romain ${ }^{55}$. Pour Honorius, le triomphe est même double, puisque Claudien offre au jeune prince, à l'occasion de la victoire sur Alaric, une sorte de rattrapage du triomphe sur Gildon qu'il n'a pas célébré (6 Honor. 103-112) :

... duo namque fuere

Europae Libyaeque hostes: Maurusius Atlas

Gildonis Furias, Alaricum barbara Peuce

Nutrierat, qui saepe tuum spreuere profana

Mente patrem. Thracum uenienti e finibus alter

Hebri clausit aquas; alter praecepta uocantis

Respuit auxiliisque ad proxima bella negatis

Abiurata palam Libyae possederat arua:

Quorum nunc meritam repetens non immemor iram

Suppliciis fruitur natoque ultore triumphat.

« Il y eut deux ennemis, en Europe et en Libye : l'Atlas Maure avait nourri les Furies de Gildon, et la barbare Peucè, Alaric, qui souvent, dans leur esprit sacrilège, n'eurent que mépris pour ton père. L'un, alors qu'il venait des confins de la Thrace, lui ferma les eaux de l'Hèbre; l'autre rejeta ses ordres alors qu'il l'appelait et, après lui avoir refusé des secours pour la guerre toute proche, abjurait ouvertement son autorité et se rendait maître des champs libyens : il n'avait pas oublié ces outrages et, revenant maintenant exercer sa juste colère, il jouit de leur supplice et, dans son fils qui est son vengeur, il triomphe.» 
La venue d'Honorius à Rome réactive donc chez le prince triomphateur la dimension de l'imperator et c'est, sans nul doute possible, également l'une des clés des adventus précédents ${ }^{56}$. Mais il faut aller plus loin et souligner ce que cette dimension du princeps imperator peut avoir de spécifiquement romain, au sens non plus orbocentrique mais bien urbocentrique ${ }^{57}$. S. MacCormack exprime cette idée de manière particulièrement suggestive et juste: " the Adventus in Rome was more elaborate than elsewhere, not only because it replaced the former triumph, but also for more important if more intangible reasons. It was the linking of two fates. Roma and Augustus had been associated in cult and otherwise in order to give expression to a whole range of sentiments that stressed the dependence of the welfare of the state on the welfare of the emperor ${ }^{58}$.» La ville même de Rome constitue ainsi le point où l'énergie impériale vient se régénérer pour le bien de l'univers. Que Claudien ait intentionnellement insisté sur cette idée pour modeler l'image d'Honorius en 404 est aisé à prouver, et nous reprenons ici la démonstration, parfaitement convaincante, de M.-F.GuipponiGineste $^{59}$, en en soulignant les éléments essentiels à notre propos. Parce que Rome est entièrement peuplée de numina, elle est le foyer légitime de l'autorité du prince (6 Honor. 39-44) :

Non alium certe decuit rectoribus orbis

Esse larem, nulloque magis se colle potestas

Aestimat et summi sentit fastigia iuris ;

Attollens apicem subiectis regia rostris

Tot circum delubra uidet tantisque deorum

Cingitur excubiis!

«Il n'y a pas dans le monde un foyer plus digne de ses maitres, sur nulle autre colline le pouvoir ne prend mieux sa mesure et n'éprouve le sentiment d'être dans la plénitude et le sommet de son droit; le palais impérial levant sa tête au-dessus des rostres que l'on voit en dessous ${ }^{60}$ contemple autour tant de sanctuaires et est entouré des demeures de tant de dieux ${ }^{61}$."

Rome est par essence la mère-patrie du prince parce que c'est elle qui le constitue comme prince. Hors de Rome, le pouvoir du prince est en exil, car il est coupé de la source même qui le vivifie (6 Honor. 407-408) :

Quem, precor, ad finem laribus seiuncta potestas

Exulat imperiumque suis a sedibus errat?

"Jusqu'à quand, je le demande, le pouvoir institutionnel se coupera-t-il et s'exilera-

$\mathrm{t}$-il de ses propres Pénates, tandis que le Pouvoir suprême erre loin de sa demeure ${ }^{62}$

$? »$

41 En retour, la Ville reçoit de la présence du prince comme un surcroît de protection divine (6 Honor. 611-612) :

o quantum populo secreti numinis addit

Imperii praesens genius!

«Oh quel surcroît de mystérieuse faveur divine la présence du génie de l'Empire apporte-t-elle au peuple!»

Même si le poète ne semble désigner ici que le peuple de Rome, l'usage du terme populus (qui n'est pas synonyme du uulgus qui ira ensuite contempler le prince au cirque $^{63}$ ) indique clairement que la relation n'est pas une relation seulement avec la Ville, mais avec le pouvoir universel qu'elle détient ${ }^{64}$. Ainsi, la venue d'Honorius à Rome est pensée comme une réactivation de la tradition romaine en tant que cette tradition assure la prospérité et le triomphe de la Ville ${ }^{65}$. Le voyage qui conduit Honorius à Rome, avec ses haltes symboliques au temple de Fortuna (Fanum Fortunae, Fano) près du 
Métaure, aux sources du Clitumne, à Narnia et jusqu'au Pater Tiberis, peut en effet se lire comme un itinéraire initiatique qui plonge le jeune prince dans les fondements mêmes de la romanité6.

C'est ce modelage romain du prince que M.-F. Guipponi-Gineste résume parfaitement en écrivant: «Claudien a singulièrement mis en valeur la personne même d'Honorius en retraçant un véritable parcours humain qui transforme le jeune homme en un princeps selon les vœux du poète. Car dans ce panégyrique s'exprime le désir d'un retour aux sources républicaines idéalisées et le poète présente au prince un miroir d'une certaine audace, bien éloigné certainement de la réalité, mais en accord profond avec le rêve si fécond de Roma aeterna. »

De fait, cette venue d'Honorius à Rome ne doit pas être seulement interprétée à la lumière des aduentus impériaux du $\mathrm{IV}^{\mathrm{e}}$ siècle comme l'illustration d'un mode particulier, transplanté à Rome, du cérémonial de cour, ni comme la simple traduction de ce cérémonial dans un spectacle romain ${ }^{67}$. Mise en rapport avec les propos tenus par le Théodose de Claudien - et à un degré moins pertinent sans doute avec le discours de Synésius qui tente de faire gouverner réellement Arcadius -, cette venue du prince à Rome, loin de perpétuer, comme on l'a parfois écrit, l'épiphanie d'un empereur-enfant qui règnerait sans gouverner, s'apparente clairement à la venue de Théodose à Rome, non pas parce qu'Honorius montrerait à nouveau au peuple l'enfant que lui avait fait acclamer son père ${ }^{68}$, mais pour souligner que cet enfant est désormais capable d'assumer le pouvoir impérial à la manière même de Théodose. Honorius adulte peut reconstruire dans la tradition romaine les rapports du prince et de la Ville, en réfutant le modèle du prince fainéant enfermé dans son palais et réduit à des fonctions de représentation. Mis en rapport avec les venues de Constance II et Théodose, le séjour d'Honorius à Rome souligne un autre élément important: pour chaque venue précédente, il s'agissait d'asseoir dans la capitale un pouvoir récemment acquis sur un usurpateur. Pour Honorius, il s'agit d'affirmer le triomphe des Romains sur un peuple étranger (les Goths d'Alaric), comme signe d'un renouveau ${ }^{69}$.

Or la stabilité et la puissance militaire qui concrétiseront ce renouveau ne peuvent fonctionner que si le prince bénéficie du soutien inconditionnel de l'aristocratie italienne, et en particulier du sénat romain. La présence prolongée du prince à Rome redonne évidemment à l'illustre assemblée une prééminence au moins symbolique sur les fonctionnaires de la cour dans la mise en scène d'une forme de partage du pouvoir ${ }^{70}$. On comprend alors le soin mis par Claudien à respecter le délicat équilibre dans l'image du prince entre le dominus et le ciuis, équation propre à la présence du prince à Rome, mais devenue ici la clé de l'efficience politique du discours ${ }^{71}$ : cet équilibre configuré et mis en scène par le panégyriste trouve sa parfaite expression dans la formule de la conclusion (6 Honor. 641-642) :

iam Thybris in uno

Et Bruti cernit trabeas et sceptra Quirini.

« Désormais en un seul, le Tibre voit la trabée de Brutus et le sceptre de Quirinus. »

C'est dès lors dans la mise en texte de cette alliance entre le pouvoir "monarchique " $\mathrm{du}$ prince et l'exercice des vertus politiques, non tant «républicaines» que traditionnellement liées aux optimi principes, qu'il faut lire la figure impériale d'Honorius dans ce dernier panégyrique de Claudien, mais en prenant bien soin de se souvenir qu'elle est l'aboutissement de plusieurs étapes du portrait princier depuis 396, 
l'adventus romain étant la mise en évidence concrète des principes énoncés par Théodose dans son adresse à son fils.

\section{Les devoirs d'un prince romain}

47 Plusieurs éléments qui expliquent l'attitude d'Honorius en 404 découlent évidemment de la construction, soigneusement orchestrée depuis l'accession au pouvoir du jeune prince, d'une figure impériale où la majesté du prince est strictement mise en balance avec la conscience que celui-ci a de ses devoirs, et donc avec une forme d'autolimitation de son pouvoir et de sa majesté. À Rome, cette représentation culmine dans la figure du princeps-ciuis. Or, depuis le De clementia de Sénèque et le Panégyrique de Trajan de Pline le Jeune, il s'est forgé une sorte de catalogue des vertus du prince romain et de modèles d'attitudes qui, appliquées à un prince, signent sa qualité de bon empereur et, déniées, le classent parmi les tyrans. Or la figure du Sénèque, qui avait tenté de faire de Néron un prince parfait, sous-tend la construction du discours de Théodose et la gens de Trajan est donnée par Claudien comme celle dont est également issu Théodose (4 Honor 19). Il y a là évidemment une intention qu'il nous faut tenter d'élucider en examinant la manière dont les vertus « romaines » investissent la représentation d'Honorius.

Parmi les vertus qui doivent être celles du prince et qui ont été bien mises en évidence par A. Wallace-Hadrill ${ }^{72}$, certaines sont des vertus strictement morales, d'autres des vertus plus comportementales, traduction en actes de vertus morales. Dans les deux cas d'ailleurs (et de façon strictement logique comme nous l'avons vu), certaines vertus s'apparentent plutôt à la conception du prince-monarque (en tant qu'il doit d'abord se gouverner lui-même), d'autres à celle du prince-citoyen (en tant qu'il côtoie ses ciues et entre avec eux dans un système de relations). Dans la catégorie des vertus monarchiques se place au premier rang la moderatio, avec des vertus qui lui seront associées comme modestia, humanitas, uerecundia, reuerentia ${ }^{73}$. Ces vertus morales ouvrent sur des vertus pratiques comme comitas ou benignitas. Dans la catégorie des vertus du prince-citoyen se place au premier rang la ciuilitas qui se définit comme la vertu qui "aptly evokes the behaviour of a ruler who is still a citizen in a city of citizens, where the freedom and standing of the individual citizen is protected by the law, not the whim of an autocrat ${ }^{74}$ " et dont découleront divers comportements pratiques, comme le fait de tolérer des plaisanteries, voire de plaisanter soi-même avec les autres citoyens, de leur parler amicalement, d'aller chez eux, de se laisser approcher ${ }^{75}$. Deux passages essentiels de Pline (Pan. Tra. 61 et 71) montrent qu'il ne faut pas voir les vertus monarchiques comme s'opposant aux vertus du ciuis, mais bien comme s'articulant avec elles de manière unique dans la personne tout aussi unique du prince. Dans le deuxième texte, Trajan montre modestie et respect envers les nouveaux consuls $^{76}$ et le sénat, manifestant ainsi son absolu respect de la fonction consulaire et de l'autorité du sénat ${ }^{77}$, et s'opposant à l'attitude des tyrans ${ }^{78}$. Le premier texte éclaire cette attitude du prince qui, quand il se comporte en citoyen ou en sénateur, ne s'abaisse pas vers ses inférieurs mais les élève à lui (Pline le Jeune, Pan. Tra. 61) :

Illos tamen tu, quamquam non potuisti tibi aequare, quum velles, adeo in edito collocasti, ut tantum super ceteros, quantum infra te cernerentur.

«Ces consuls cependant, bien que tu n'aies pu les faire tes égaux alors que tu le voulais, tu les as placés si haut qu'on les voit dépasser tous les autres d'autant qu'ils sont dépassés par ta personne. » 
vertus du prince ciuis n'abolissent donc pas la grandeur de l'empereur, elles l'incarnent dans le respect d'un système social et hiérarchique préexistant dont l'empereur se pose en garant. Comme le notait A. Wallace-Hadrill (1982, p. 47), « an emperor whom ritual raised over the level of human society [...] owed nothing to the internal structure of the society he ruled. To act, by contrast, as a member of that society, as the peer of its most elevated members, was (symbolically) to associate autocratic power with the social structure. » C'était donc concilier les deux aspects de sa fonction de manière politiquement et socialement efficiente ${ }^{79}$.

Tous ces éléments se retrouvent dans la présentation que Claudien donne du prince et/ ou s'incarnent dans son adventus romain, le plus souvent en contrepoint d'autres modèles de gouvernement, comme en 6 Honor. 547-550:

Temnunt prisca senes et in hunc sibi prospera fati

Gratantur durasse diem moderataque laudant

Tempora, quod clemens aditu, quod pectore solus

Romanos uetuit currum praecedere patres :

"Les anciens dédaignent désormais le passé et ils louent les prospérités du destin et

la modération des temps d'avoir vécu jusqu'à ce jour où un prince si clément dans son abord et son cœur a seul interdit que les sénateurs de Rome marchent devant son char. »

Cette évocation de la déférence d'Honorius pour le sénat provoque immédiatement ce commentaire sans doute directement dirigé contre Constance II (6 Honor. 558-559) :

Idque inter ueteris speciem praesentis et aulae

Iudicat : hunc ciuem, dominos uenisse priores.

«On juge par ce fait de l'aspect de l'ancienne cour et de l'actuelle : notre prince

vient en citoyen, ceux qui sont venus avant l'ont fait en maîtres. »

(6 Honor. 63-64):

publicus hinc ardescit amor, cum moribus aequis

inclinat populo regale modestia culmen.

«Voilà ce qui enflamme l'amour <du prince> dans l'État, quand, le caractère plein

d'équité, il incline par modestie sa royale hauteur jusqu'au peuple. »

La moderatio qui caractérise le prince se traduit alors en humanitas et en ciuilitas, le prince prenant plaisir au contact avec ses sujets. On notera d'ailleurs ici que c'est la figure de Théodose qui réapparaît pour enseigner, par la pratique de son adventus de 389, ce que doit être l'adventus de son fils (6 Honor. 54-62) :

Haec sunt, quae primis olim miratus in annis

Patre pio monstrante puer. nil optimus ille

Diuorum toto meruit felicius aeuo,

Quam quod Romuleis uictor sub moenibus egit

Te consorte dies, cum se melioribus addens

Exemplis ciuem gereret terrore remoto,

Alternos cum plebe iocos dilectaque passus

Iurgia patriciasque domos priuataque passim

Visere deposito dignatus limina fastu.

«Ce sont ces pénates que l'enfant que tu étais admira dans ses jeunes années tandis que ton père aimant te les montrait. Il n'est rien qui fit plus mériter à cet excellent prince (optimus) l'honneur d'être rangé parmi les dieux dans toute sa vie que le fait que, victorieux, il passa avec toi des jours dans les murs de Rome, quand, ajoutant son nom aux exemples des meilleurs princes, sans plus de terreur, il se comportait comme un citoyen, acceptait d'échanger des plaisanteries avec la plèbe, de prendre 
part à leurs discussions, et daignait partout rendre visite aux demeures des

sénateurs comme des simples particuliers, en laissant de côté tout faste.» parce qu'il laisse entrevoir la cohérence idéologique du projet stiliconien, dont Honorius n'est qu'une partie. Il ne faudrait pas se méprendre sur l'octroi des vertus princières de uerecundia et de grauitas au général et considérer que Stilicon veut substituer sa propre image à celle d'Honorius. On pourrait pourtant le penser à la lecture du long passage à la gloire de Stilicon qui constitue le centre du Panégyrique sur le sixième consulat d'Honorius où Alaric lui-même reconnaît la puissance victorieuse de son ennemi, avant que l'éloge ne vienne de la propre bouche du prince, avec ces paroles, certes troublantes, mais à interpréter avec prudence (6 Honor. 429-434) :

\footnotetext{
Sed nec post Libyam (falsis ne perge querellis

Incusare tuos) patriae mandata uocantis

Spreuimus : aduectae misso Stilichone curules,

Vt nostras tibi, Roma, uices pro principe consul

Impleret generoque socer. uidistis in illo

Me quoque;

« Mais même après la Libye (cesse donc d'accuser tes enfants de plaintes infondées), nous n'avons pas dédaigné les demandes de notre patrie qui nous appelait : le siège curule est venu jusqu'à nous quand nous avons envoyé Stilicon pour qu'il remplisse, ô Rome, notre rôle pour toi, consul à la place d'un prince, beau-père à la place d'un gendre. En lui, c'est moi aussi que vous avez vu. »
}

Replacé dans l'ensemble de la construction qui nous occupe, ce passage peut être lu avec la nuance qui, pensons-nous, lui convient. Si Stilicon a pu « remplacer » Honorius, c'est bien en vertu de son double lien au prince, en tant que monarque et en tant que citoyen romain. Pour ce qui est de l'aspect monarchique, Stilicon est apparenté à Honorius par le mariage du prince avec sa fille Marie, il est donc un membre de la domus sacra, la famille impériale. Mais en lui donnant le consulat, Honorius traduit, en même temps que la gloire de Stilicon, son respect pour les institutions romaines car, dans un même geste, il entérine les exploits du général par l'octroi de la magistrature

Interférences, 9 | 2016 
suprême et illustre son respect de la magistrature suprême par la désignation d'un homme à la vertu incontestable. Si Stilicon, consul en 400 , succède en Occident à un philosophe et intellectuel de premier plan, Mallius Theodorus, à la vertu irréprochable (selon Claudien), il corrige aussi l'aberration de l'Orient qui avait osé nommer consul en 399 un eunuque, Eutrope, que Claudien s'empresse de déchirer dans un pamphlet et que l'Occident avait refusé de reconnaître. Rappeler le consulat de Stilicon en 404, et indiquer en 400 que le grand homme l'a refusé jusqu'à ce que Rome elle-même le supplie, participe donc d'une même mise en scène du pouvoir en Occident, comme un pouvoir qui replonge dans ce que la tradition romaine a de meilleur. Le prince, qui s'efforce d'être fidèle à l'enseignement de Théodose et à l'exemple des optimi principes, s'inscrit dans un cercle vertueux où ses proches sont pénétrés du même idéal que lui et du même sens aigu du mos maiorum. Loin de nuire à la grandeur d'Honorius, cette articulation de son pouvoir impérial avec celui de son général (puis du sénat et des autres corps de l'État) souligne les bienfaits de la moderatio impériale, visibles d'ailleurs dans les succès éclatants (au moins dans leur version claudianénne) remportés contre Alaric ${ }^{81}$.

Nous pouvons donc lire l'ensemble de cet adventus comme une pièce supplémentaire d'un puzzle qui semble clairement nous orienter vers ce constat: il y a, peut-être depuis Théodose lui-même (avec Pacatus), et à coup sûr pour Honorius, une volonté dans l'entourage le plus influent du prince de mettre en valeur les éléments les plus traditionnels du pouvoir impérial, en posant comme contre-modèles à la fois l'exercice du pouvoir par un prince comme Constance II et la manière supposée dont l'exerce Arcadius. Il est évident que, dans ce travail idéologique, le rapport que le prince d'Occident entretient avec celle qui est la Ville par excellence fournit un élément décisif, et ce, d'autant que le rapport que le prince d'Orient entretient avec Constantinople ne peut être, pour des raisons à la fois historiques et culturelles, que fort différent.

\section{Problématiques nouvelles autour du statut de la Ville}

Si le rapport des princes avec leurs capitales respectives est ici un élément à prendre en compte, c'est évidemment parce qu'il est l'objet d'une construction idéologique complexe, qui permet en retour de mettre en lumière un aspect fondamental que Claudien passe totalement sous silence : le rapport qui s'est tissé au cours du IV siècle entre la figure du prince et la religion chrétienne ${ }^{82}$. Or c'est bien dans l'analyse du rapport aux deux capitales, Rome et Constantinople, que, pour l'Occident en tout cas, apparait une nouvelle forme de tension cette fois entre la reconfiguration du prince en optimus princeps sur le modèle de Trajan et le statut du christianisme en tant que religion de l'empereur ${ }^{83}$. Nous analyserons d'abord le rapport ambigu du prince occidental à la Ville, en comparant les données que nous avons isolées dans les parties précédentes avec les actes concrets posés par Honorius lors de ses venues à Rome puis avec l'image que la pensée politique orientale construit des rapports entre le prince et Constantinople; nous poserons ensuite la question de l'autorité du prince sur l'Empire en montrant, en particulier avec les propos de Rutilius, comment le recentrage sur Rome de la figure princière échoue en réalité à refonder une forme d'unité de l'Empire autour de la personne impériale, pour enfin montrer, à partir de Rutilius et de données contemporaines du De reditu suo, que l'échec de la reconfiguration de la figure impériale 
signe, en tout cas dans le milieu païen de Rutilius, l'affirmation d'une nouvelle forme de romanité qui se pense désormais en dehors de l'institution impériale.

\section{Les princes en leurs villes : Rome, Constantinople et les modèles princiers}

Le premier constat qui s'impose est que la perception de la Ville peut être fondamentalement différente pour un oriental et pour un occidental. Pour un oriental, Rome représente moins une ville, un lieu, qu'un système politique unificateur, l'idée de Rome, fût-elle éternelle, est pensée comme une forme de métonymie du système sociopolitique romain qui a unifié l'Empire. Cette idée se retrouve en Occident dans l'exaltation par exemple de la Roma aeterna comme expression de la pérennité de l'Empire et de son modèle, mais elle se trouve évidemment en concurrence avec la représentation géographique concrète d'une ville réelle, Rome, capitale politique de l'Empire et résidence impériale pendant trois siècles, ainsi qu'avec une représentation religieuse qui fait des cultes romains le fondement surnaturel de la puissance romaine ${ }^{84}$. Or, si la Ville a perdu son statut de résidence impériale depuis plus d'un siècle, les tenants de la religion traditionnelle n'en ont pas conclu, bien au contraire, que la protection divine attachée à l'espace sacré de Rome s'était déplacée avec la cour. Pour eux, comme en témoigne l'affaire de l'autel de la Victoire qui se déroule en 384 mais est réactivée en 402 , l'espace surnaturel de Rome et les numina qui y résident demeurent la condition essentielle et vitale de la survie d'un Empire qui, privé de cet espace, se trouverait sans défense divine contre ses ennemis ${ }^{85}$.

61 Si l'on peut évidemment interpréter ainsi l'affaire de l'autel de la Victoire, il n'y a aucune raison que l'on n'interprète pas selon le même schéma les déclarations de Claudien dans le Panégyrique sur le sixième consulat d'Honorius, et en particulier l'ouverture placée sous le signe de Fortuna Redux (6 Honor. 1-5) :

Aurea Fortunae Reduci si templa priores

Ob reditum uouere ducum, non dignius umquam

Haec dea pro meritis amplas sibi posceret aedes,

Quam sua cum pariter trabeis reparatur et urbi

Maiestas...

«Si les Anciens consacrèrent un temple d'or à Fortuna Redux, pour le retour de leurs généraux, cette déesse n'aurait jamais pu plus dignement demander en récompense de ses mérites un vaste sanctuaire que maintenant que leur grandeur est restituée pareillement à la trabée et à la Ville. »

Certes, la formulation de Claudien demeure ambiguë et la forme posceret peut souligner que cette tradition cultuelle est renvoyée dans le monde de l'ancienne Rome ${ }^{86}$, mais il ne serait guère habile de choisir le culte précis de Fortuna pour en faire un simple artifice littéraire. Il semble au contraire que le poète, tout en indiquant que cette interprétation peut ne pas être celle du prince lui-même, laisse ouverte une lecture de la venue d'Honorius à Rome qui prendrait sens dans la tradition cultuelle romaine ${ }^{87}$. Claudien ménage bien ici une lecture romaine de l'adventus que tout le reste du panégyrique va confirmer, et qui permet aux adeptes de la religion traditionnelle de voir dans les actes du prince l'accomplissement d'un rituel qui réactiverait la protection divine sur la Ville et l'Empire ${ }^{88}$. Ainsi que le notait très justement S. MacCormack, une telle attitude du poète pouvait être particulièrement adroite dans la mesure où elle reconstruisait le lien originel entre la forme impériale du pouvoir 
(restaurée dans son exercice par les optimi principes, comme nous l'avons vu) et la religion romaine, mais sur un mode " ouvert ", qui laisse place à une lecture cultuelle si l'on est adepte de ces cultes (le prince accomplit les gestes qu'il faut), ou à une lecture simplement culturelle si l'on est chrétien (le prince ne croit pas en ces fables, mais respecte le protocole le plus traditionnel en signe d'une volonté restauratrice qui serait strictement politique $\left.{ }^{89}\right)$.

Or plusieurs indices montrent que cette double lecture (lecture ad gentes et lecture ad Ecclesiam pourrait-on dire) est probablement la bonne. Avant d'en venir aux indices présents dans ce que nous savons d'éléments du séjour d'Honorius à Rome non mentionnés par Claudien, il nous semble important de prendre en compte un passage de Rutilius récemment éclairé.

Parlant du sénat de Rome, en 417, Rutilius mentionne son Genius dans une évocation qui souligne la dimension assimilatrice de l'auguste assemblée (De reditu suo 1,13-18) :

Religiosa patet peregrinae Curia laudi, Nec putat externos quos decet esse suos;

Ordinis imperio collegarumque fruuntur Et partem Genii quem uenerantur habent Quale per aetherios mundani uerticis axes Concilium summi credimus esse dei.

«La vénérable Curie s'ouvre au mérite venu du dehors; elle ne considère pas comme étrangers ceux qui sont dignes de lui appartenir. Ils jouissent de l'autorité de cet ordre, de l'autorité de leurs collègues ; ils ont une part à l'influence du Génie qu'ils vénèrent. Tel, croyons-nous, le conseil du dieu suprême se réunit-il dans les voûtes célestes de l'univers » (trad. É. Wolff).

Une inscription, CIL VI 41378, analysée il y a peu par P. Bruggisser, confirme de façon définitive que Rutilius ne se livre pas ici à une comparaison mythologique ou à un jeu d'érudition antiquaire, mais renvoie bel et bien à une réalité cultuelle contemporaine, matérialisée dans le lieu même où se réunit le sénat par l'inscription concernée ${ }^{90}$. Si l'un des noms cités, pour lequel il propose Vettius Agorius Praetextatus, demeure très problématique en raison de l'état très fragmentaire de cette partie du texte ${ }^{91}$, il n'en demeure pas moins que ce qu'écrit Rutilius possède un lien direct avec une réalité cultuelle, ce qui rend bien improbable l'utilisation de Fortuna Redux par Claudien, moins de dix ans plus tôt, comme une pure fiction littéraire. "La mise en valeur du Génie du Sénat de Rome sur l'édifice de la Curie procède de la conscience que les milieux sénatoriaux développent de leur rapport au divin. La vénération marquée pour le Génie du Sénat de Rome s'accorde pleinement avec la personnalité de Rutilius Namatianus, qui partage intimement les idéaux de l'aristocratie sénatoriale ${ }^{92}$ », ou au moins d'une partie d'entre elle. Et cette conscience romaine traditionnelle du lien entre le sénat, la cité, les dieux civiques et la protection de l'Empire éclaire analogiquement la présence dans le Panégyrique sur le sixième consulat d'Honorius d'éléments de la religion traditionnelle de la Ville de Rome.

Or, de manière apparemment paradoxale, cette lecture traditionaliste du panégyrique trouve sa confirmation dans ce que Claudien ne nous dit pas de l'adventus, mais dont nous avons par d'autres sources le récit: la venue d'Honorius au tombeau de saint Pierre nous est connue par un passage d'un sermon d'Augustin. Or celui-ci oppose précisément les deux modalités de l'adventus (Serm. Dolbeau, 25, 25) :

Veniunt, ut dicere coeperam, reges Romam. Ibi sunt templa imperatorum qui superbia sua diuinos sibi honores exegerunt ab hominibus et, quia poterant - reges enim erant et dominatores-, extorserunt potius quam meruerunt. Cui potuit tale aliquid extorquere 
piscator? Ibi est sepulcrum piscatoris, ibi templum est imperatoris. Petrus ibi est in sepulcro, Hadrianus ibi est in templo. Templum Hadriani, memoria Petri. Venit imperator. Videamus quo currerit, ubi genua figere uoluit: in templo imperatoris, an in memoria piscatoris? Posito diademate, pectus tundit ubi est piscatoris corpus, cuius merita cogitat, cuius coronam credit, per quem cupit peruenire ad deum, cuius orationibus se adiuuari sentit et inuenit.

"Les souverains, comme j'ai commencé à le dire, viennent à Rome. Il y a là les temples des empereurs qui, en raison de leur orgueil, exigèrent des hommes que leur soient accordés des honneurs divins, et, parce qu'ils en avaient le pouvoir (ils étaient en effet des souverains et avaient une autorité absolue), ils extorquèrent cet honneur plus qu'ils ne le méritèrent. À qui un pêcheur aurait-il bien pu extorquer quelque chose de tel ? D'un côté il y a la tombe d'un pêcheur, de l'autre le temple d'un empereur. D'un côté il y a Pierre dans la tombe, de l'autre Hadrien dans le temple. Un temple pour Hadrien, un mémorial pour Pierre. Voici l'empereur. Voyons où il s'est précipité, où il a voulu fléchir le genou: dans le temple de l'empereur ou sur le mémorial du pêcheur? Il a déposé son diadème, il s'est frappé la poitrine là où est le corps du pêcheur : il songe aux mérites de ce dernier, il met sa foi en sa couronne grâce à laquelle il désire parvenir jusqu'à Dieu, car il sent et il découvre que ce sont les prières du pêcheur qui le soutiennent. »

Même si on ne lit pas la mention d'Hadrien comme une forme de réponse à la fin du Panégyrique sur le sixième consulat d'Honorius ${ }^{93}$, la remarque d'Augustin est loin d'être incidente pour notre réflexion. Elle se place dans une autre forme de modelage de la figure princière, cette fois en milieu chrétien, et qui crée entre la Ville et le prince une autre forme de relation cultuelle, qui se manifeste également dans la construction du mausolée d'Honorius sur la colline vaticane, tout près de la basilique Saint-Pierre, à un moment que l'on peut situer entre 400 et 408 . Cette construction est d'autant plus importante qu'elle est contemporaine de l'édification par Arcadius de son propre mausolée près de l'église des Saints-Apôtres de Constantinople ${ }^{94}$. Plus qu'une improbable compétition entre les frères ${ }^{95}$, à un moment où leurs relations se sont d'ailleurs améliorées, cette entreprise relève d'une volonté de renforcer, entre le christianissimus princeps et Rome, un lien qui se rapproche de celui que Constantinople entretient avec le basileus chrétien, dans une idéologie d'association entre figures apostoliques et figures impériales comme modèles de disciples du Christ ${ }^{96}$. En même temps, ce type de représentation du prince comme pius au sens chrétien du terme manifeste la relation privilégiée que le pouvoir impérial tisse avec l'Église, comme en témoignent également les travaux réalisés à Saint-Paul-hors-les-murs, basilique dont un passage de Prudence laisse supposer qu'elle a été également visitée par Honorius en $404^{97}$.

Dans ce contexte, la figure de l'empereur chrétien à Rome s'apparente bien plus nettement à celle de l'empereur d'Orient et au lien avec Constantinople que les théologiens et penseurs byzantins formalisent sous le thème de la Nouvelle Jérusalem, siège du prince chrétien, que ne souille aucune superstition ancienne ${ }^{98}$. Deux éléments soulignent la tension qui peut exister entre ce modèle et celui de l'optimus princeps tel que nous l'avons défini plus haut dans un contexte strictement romain.

Le diptyque consulaire de Constance, qui date de 417 comme le voyage du De reditu $s u 0^{99}$, nous paraît en effet formaliser à la fois l'unité de la représentation impériale, que l'on soit à Rome ou à Constantinople, et marquer une forme de différenciation qui souligne que, malgré les tentatives de christianiser le rapport du prince avec Rome, le lien n'est peut-être pas perçu aussi directement que le rapport du basileus avec la capitale orientale. 

leurs capitales respectives. Rome, à gauche, y est figurée en guerrière casquée tenant en main le globe et la lance et portant le glaive au côté, représentation absolument traditionnelle, tandis que Constantinople est représentée avec une couronne de rayons. Les deux villes sont nimbées. La différence essentielle réside dans l'attitude de Constantinople dont la main droite est appuyée sur l'épaule du prince (Théodose II) dans un geste que l'on peut interpréter comme étant d'affectueuse protection. Il s'exprime sans nul doute ici ce que S. MacCormack appelait « particular and deeply-felt convictions ${ }^{100}$ ", qu'il est difficile, compte tenu de la piété universellement admise de Théodose II, de ne pas relier au caractère de capitale chrétienne, voire pour ainsi dire d' urbs christianissima, de la seconde Rome ${ }^{101}$.

Or il est tout aussi évident que cette configuration princière orientale a exercé sur Honorius une influence notable puisque, dans un autre diptyque consulaire plus ancien, le célèbre diptyque de Probus en 406, Honorius est représenté en tenue militaire tenant un étendard portant le chrisme et accompagné de la légende in nomine Xpi uincas semper, "puisses-tu toujours vaincre au nom du Christ». Or cette légende est unique dans un contexte de diptyque dont les représentations et les légendes demeurent strictement traditionnelles ${ }^{102}$ et marque un souci, pour le camp chrétien, d'asseoir la légitimité de sa représentation du prince.

On peut donc aisément tirer de ce qui précède trois conclusions.

1. La période 397-404 (au moins, mais sans doute bien après, comme on le voit encore avec Rutilius) est marquée par une double tentative de configuration du pouvoir impérial, soit en un sens romain traditionnel, soit en un sens chrétien, ce qui témoigne probablement d'influences différentes, voire contradictoires, et de conflits d'intérêts dans la cour d'Occident qui nous sont connus par d'autres sources comme le Contre Symmaque de Prudence. Ces influences peuvent recouper d'un côté une volonté de rupture par rapport au modèle post-constantinien d'exercice du pouvoir introduit par Théodose, de l'autre la volonté, au moment où le christianisme triomphe dans la législation impériale, de "pousser l'avantage » en exprimant de manière plus forte encore que par le passé une théologie du pouvoir impérial que l'on voit s'affirmer en Orient.

2. Ce travail de modelage de la figure du prince présente, au tournant $d u v^{e}$ siècle, un caractère contradictoire dû probablement au fait que les deux imageries se superposent, voire se combattent, dans les luttes d'influences de la cour. C'est ce qui explique la perplexité des modernes devant l'apparente confusion des signes, puisque l'on voit le même prince représenté dans ce qui semble être la reviviscence d'un cérémonial typiquement romain et en même temps dans la figure d'un christianissimus princeps. Cette contradiction était-elle perçue par les contemporains? Le débat reste ouvert, mais il semble en tout cas que l'une des voies proposées par les modernes pour la supprimer ne soit pas pertinente : considérer que les actes chrétiens du prince disent la réalité du pouvoir et les actes "traditionnels » une fiction plus ou moins littéraire destinée à contenter quelques élites traditionalistes est sans nul doute une lecture réductrice. Le fait qu'Augustin et Claudien semblent, alors qu'ils décrivent le même événement, en avoir une perception totalement différente accrédite la thèse d'une 
forme de fracture ouverte en 404, ou au moins d'une impossibilité de dégager une image unique, consensuelle du prince, dont la figure demeure brouillée, car tiraillée entre les deux pôles de représentation qu'on lui fait alternativement, voire en même temps, endosser ${ }^{103}$.

3. La personnalité peu marquée d'Honorius, d'abord prince-enfant, puis prince falot et manœuvrable ${ }^{104}$, permet sans doute une exacerbation des enjeux de pouvoir et des luttes d'influence qui se voit dans des tentatives pour modeler l'image de ce prince en devenir au gré d'intérêts et de représentations variées. Il se dégage toutefois de la lecture des panégyriques successifs de Claudien la vision d'un modèle théodosien de l' optimus princeps comme réactivation du modèle de Trajan, dont l'entourage d'Honorius a tenté de tirer parti pour se (ré)concilier les élites traditionnelles de Rome.

Mais il est probable que, si cela a échoué, c'est faute d'avoir pu trouver dans la représentation du prince un terrain qui puisse réconcilier en profondeur la mystique romaine du principat et la théologie politique chrétienne. Et c'est sans nul doute Rutilius, avec les convictions qu'il manifeste et les faits dont il est le témoin engagé, qui atteste, au moins sur le plan littéraire, la profondeur de cet échec.

\section{Image du prince et/ou autorité romaine : l'affirmation d'un nouveau lien à la romanité}

76 Il ne fait aucun doute que cette entreprise de modelage de la figure princière repose, en 404, sur un réel besoin politique du soutien unanime de l'Occident à un pouvoir impérial fragile, mais qui sort conforté de la victoire éclatante (ou présentée comme telle) remportée sur Alaric. Nous nous trouvons donc en 404 dans un moment où la figure princière peut, en raison à la fois de son âge (le prince étant désormais adulte) et de la conjoncture plutôt favorable, assumer réellement l'image que son entourage a voulu donner de lui, ou, à tout le moins, accréditer cette image par ses actes propres et les résultats obtenus par ses généraux. Cependant, la question du soutien global de l'Occident au prince demeure essentielle et ces victoires sont évidemment l'occasion de s'assurer de ce soutien, voire de le réactiver ${ }^{105}$.

77 Le poème de Rutilius, composé plus de dix ans plus tard, et surtout après l'échec de la défense des frontières nord qui aboutit à l'invasion de 407 qui frappe la partie ouest de l'Empire d'Occident et les activités des Goths d'Alaric en Italie qui aboutissent à la prise de Rome en 410, constitue une forme de réception littéraire indirecte de cette tentative de remodelage, dont on a déjà largement souligné le caractère éminemment politique $^{106}$. Or le discours de Rutilius peut se lire en grande partie comme une réponse (négative) aux manœuvres idéologiques et politiques illustrées par les panégyriques des années 397-404 et le programme ambigu de l'adventus romain de 404.

Dans le célèbre éloge de Rome qui ouvre le livre 1 du De reditu suo, il est absolument remarquable que la Ville apparait comme totalement dissociée des figures impériales, sans toutefois que cette dissociation ne conduise à une abstraction de la vision de Rome, au sens où la Ville deviendrait une notion isolée de sa réalité géographique et sociale $^{107}$. La Ville est bien présente dans sa matérialité, mais cette matérialité se transcende dans le destin exceptionnel de cette cité devenue la reine de l'univers. Il ne faut donc sans doute pas trop se hâter de ne voir dans cette description qu'une simple illusion de grandeur entretenue par le désir, mais plutôt y lire un véritable manifeste politique qui tend à imposer, à travers la figure même de la Ville-mère, une conception 
de la romanité qui se construit indépendamment de la figure impériale, voire en résistance à cette figure. Comme le notait $\mathrm{M}$.J. Roberts, «the figure of Roma, here detached from imperial politics or religious controversy, remains a rallying point for a Gallo-Roman aristocrat such as Rutilius [...] Rutilius has no expectation of an individual leader. He must pin his faith on the resilience and recuperative powers of the personified Roma ${ }^{108}$.» Toutefois, l'absence de controverse religieuse ou politique dans cette vision apaisée de la grandeur de Rome ne saurait signifier de la part du poète le refus d'un discours politique sur la romanité, c'est exactement le contraire qui se produit. Selon les mots très justes de S. MacCormack, "The pagan poet Rutilius Namatianus took the Christian empire, over-personalized as it had been by the Christian emphasis on the personal beliefs of the emperor, seriously. It drove him to a novel solution which we can see in his rendering of one theme: that of Roma aeterna... In this scheme, there is no room for the emperor, Christian and living at Ravenna. Rome commands the horizon ${ }^{109}$.»

Or toute la lecture du poème confirme cette idée, et nous voudrions en voir quelques exemples qui soulignent, selon nous, que le voyageur de 417 , rejetant complètement aussi bien la vision assimilatrice d'un prince chrétien pouvant être romain que la tentative de restaurer une image de l'empereur comme optimus princeps «à l'ancienne ", définit en réalité un autre critère pour la romanité, celui de l'attachement aux valeurs comme au modèle social et politique de la Ville reine du monde.

Un premier élément peut être fourni par la comparaison de l'éloge appuyé de Constance avec la diatribe contre Stilicon, au livre $2 \mathrm{du}$ De reditu suo. La découverte du fragment contenant l'éloge de Constance permet en effet de mieux comprendre la nature exacte des reproches que le poète adresse à l'ancien régent, finalement exécuté en 408. Bien qu'en partie mutilé, le texte est ouvertement à la gloire du consul de 417 (2 frg. B, 7-16) :

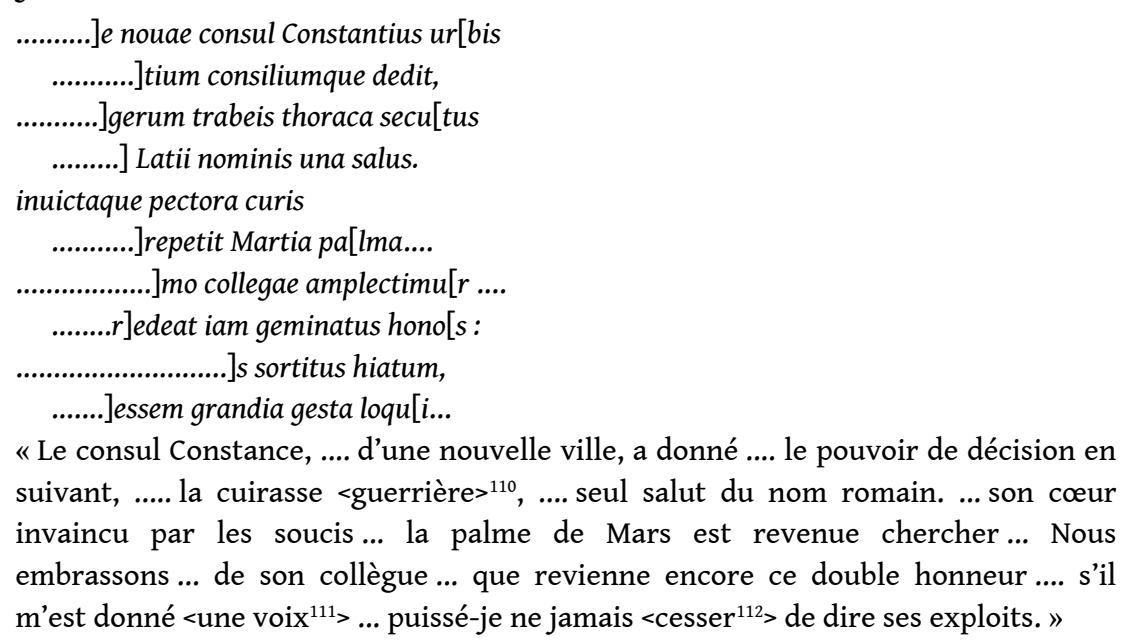

81 Que les détails d'interprétation de ce texte extrêmement mutilé soient délicats ne change rien au fait, accepté par tous, qu'il s'agit d'une forme de panégyrique de Constance, consul alors pour la seconde fois après un premier consulat en 414 , obtenu à la suite de succès en Aquitaine. La mention « le seul salut du nom romain » ainsi que la part réduite laissée à Honorius, le collègue de Constance en 417, ne doivent pas être minimisées car, dans l'invective contre Stilicon, le poète trace une image du généralissime exactement opposée à celle qu'il donne ici de Constance, sans la moindre 
allusion à une intervention impériale qui aurait pu contrebalancer la malignité de l'ancien régent (De reditu suo 2, 41-46 et 55-56) :

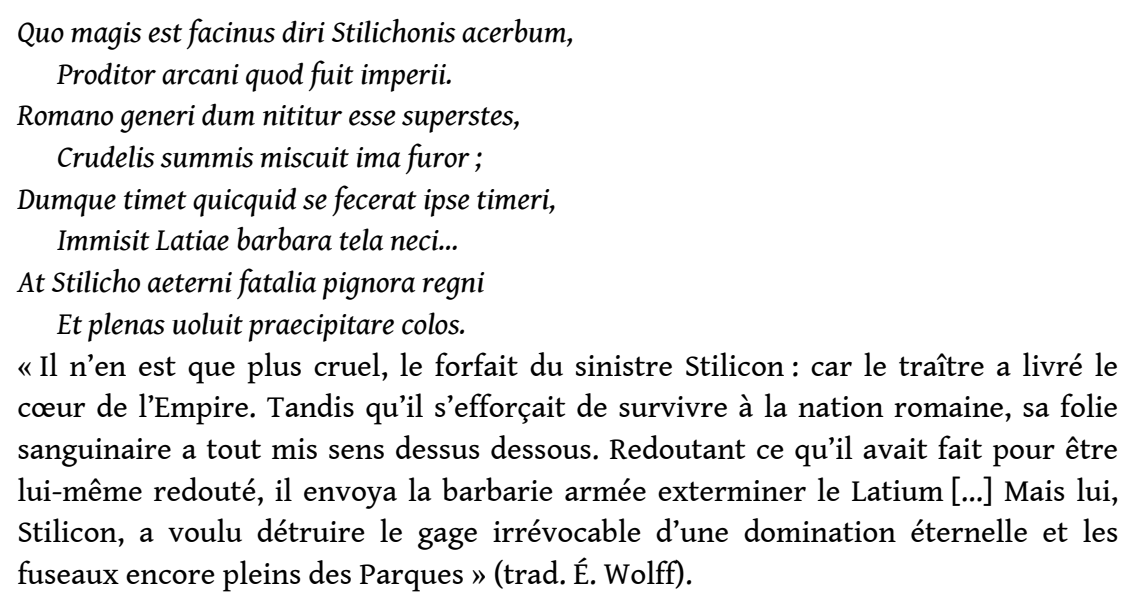

Outre le parallélisme d'expression avec, dans les deux cas, l'usage d'un dum qui met en évidence les bienfaits de Constance et la malignité de Stilicon, ces deux extraits montrent clairement l'échec de la représentation impériale, puisque la figure du prince est au mieux posée comme une figure annexe et en aucun cas comme l'acteur même de l'Histoire. Stilicon et Constance définissent donc " en creux » l'image d'un prince qui règne sans gouverner, à l'opposé de l'optimus princeps tel que tendait à le définir Théodose, relayé par la propagande honorienne des années 404, mais, évidemment, avec des résultats exactement inverses. Or, même si nous reviendrons rapidement sur les dégâts politiques prêtés à la politique stiliconienne, là n'est peut-être pas l'essentiel pour ce qui nous occupe ici. Le plus remarquable est sans doute l'opposition entre le fondateur qui (re)crée pour le Latium un modèle social traditionnel romain (noter le mot ciuibus et l'association auspicium consiliumque) et celui qui s'en prend, en brûlant les livres Sibyllins, à la Fortuna urbis elle-même, telle que les dieux l'ont prévue et telle qu'elle se manifeste dans les livres sacrés que l'ex-régent a (selon Rutilius) détruits ${ }^{113}$. Si l'on met ce sacrilège en lien avec l'autre grief, le fait d'avoir laissé les barbares ravager l'Italie, et plus généralement de leur avoir livré l'Empire, on mesure combien le discours de Rutilius est certes anti-stiliconien, mais combien également il n'épargne pas la figure d'un prince impuissant, qui ne peut agir dans l'intérêt de l'État que s'il a un général de la valeur de Constance, un vrai général romain, et qui ne peut empêcher ses mauvais ministres de mener l'Empire à sa perte.

À partir de cette lecture, il serait tentant de penser que s'est finalement imposée à la cour et aux conseillers du prince la vision monarchique d'un prince fainéant et accréditer ainsi l'idée d'un Honorius et d'une cour de Ravenne qui assistent, impuissants et finalement indifférents, à l'effondrement de l'Occident. Or cette idée serait en totale contradiction avec l'affirmation d'une reconquête et d'une défense de l'Empire qui accompagne dans le Panégyrique sur le sixième consulat d'Honorius l'image de l'optimus princeps et de son général. À moins de se ranger à une lecture absolument cynique de ce qui ne serait que des gesticulations opportunistes en 404 (lecture qui, en un sens, est celle qu'en donne Rutilius dix ans plus tard et qui a marqué les esprits, y compris ceux des modernes $\left.{ }^{114}\right)$, on ne peut admettre cette indifférence que tout dément d'ailleurs $^{115}$. Car, comme l'atteste Rutilius lui-même dans sa prière à Rome $(1,14 s q$.$) , il$ est absolument exclu que l'on ait eu affaire à un processus concerté d'abandon de l'Occident, et non à des replis jugés stratégiques et envisagés pour une durée limitée ${ }^{116}$. 
Toute la politique menée par Honorius (et qui permet d'ailleurs à Constance de se mettre en vedette) repose bien sur la volonté farouche de récupérer pied à pied, contre les barbares ou les usurpateurs, les provinces temporairement perdues. D'ailleurs, en 418, ce même Constance, héros de Rutilius, pour assurer la sécurité de l'Aquitaine, installera les Goths dans ce qui est très probablement pensé comme une mesure temporaire ${ }^{117}$, permettant de " voir venir » et d'éviter la reproduction des catastrophes dont Rutilius lui-même se fait l'écho. Or ce qui est « haute trahison» chez Stilicon ne peut être chez Constance fine politique que si l'on déplace le curseur idéologique et si l'on ne regarde plus les faits mais le sens que l'on veut leur donner en fonction d'intérêts particuliers. Et ce sont ces intérêts (compris au sens large non seulement d'intérêts matériels ou de pouvoir, mais de représentativité sociale et culturelle) que le De reditu suo nous permet de cerner, dans un ultime avatar du lien avec la tradition. modelage idéologique, qui reprend le modèle traditionnel, mais dans un tout autre sens que celui qui était porté dans l'entourage du prince? Dans l'image qui ressort du De reditu suo, le modèle impérial semble avoir failli et la reconfiguration proposée par Stilicon et Claudien n'avoir pas survécu au régent et aux troubles de la seconde décennie du siècle. Mais que met le poète à la place de ce qu'il déchire : l'inaction et la corruption des gouvernants ${ }^{118}$, l'évolution de certains chrétiens vers des mœurs qui s'opposent à l'humanitas et introduisent, sans même l'aide des barbares, la feritas au cœur même de l'Empire ${ }^{119}$ ?

La réponse figure dans le catalogue de ses amis et les vertus que leur prête le poète. Ces passages construisent une forme de portrait de la romanité, où l'on retrouve toutes les vertus que le Claudien de Théodose prêtait à l'optimus princeps, appliquées non plus à une figure impériale mais à des figures de grands nobles qui servent la romanité sans forcément servir directement le prince. Ainsi pour le jeune Rufius, ancien questeur du palais et proconsul d'Afrique, dont le poète note $(1,173-176)$ :

Rexerat ante puer populos pro consule Poenos; Aequalis Tyriis terror amorque fuit.

Sedula promisit summos instantia fasces: Si fas est meritis fidere, consul erit.

"Auparavant, encore jeune homme, il avait, comme proconsul, gouverné les Carthaginois; il inspira aux Tyriens à la fois crainte et amour. L'imitation zélée de son père lui a promis l'honneur suprême des faisceaux; si l'on peut faire fond sur les mérites, il sera consul » (trad. É. Wolff modifiée).

Tout l'enjeu de ce passage se trouve dans le dernier vers diversement compris, mais dont il nous semble qu'il désigne clairement les "mérites » personnels qui doivent élever au consulat, dans la droite ligne de l'hommage à l'action du proconsul. Ce proconsulat reprend, bien que la fonction soit devenue dans la période tardive une fonction honorifique qui relève de la sinécure, le topos du bon gouvernement de province tel qu'on le lit depuis la lettre de Cicéron à son frère Quintus (Q. fr. 2, 1). Si Rufius obtient le consulat, ce n'est pas par le fait du prince, mais par la reconnaissance (laissée hypothétique) par celui-ci chez l'impétrant des qualités de uir ciuilis.

Cette figure du gouverneur honnête et paternel qui gouverne ses provinciaux pour leur bien trouve une nouvelle illustration plus nette encore dans la figure d'Exuperantius, dont le rôle exact en Armorique n'est pas très clair ${ }^{120}$ et nous importe peu ici, mais dont il faut souligner que Rutilius le loue parce que $(1,215)$ :

leges restituit libertatemque reducit 
« il rétablit les lois, ramène la liberté » (trad. É. Wolff). clés de leges et libertas, protection de la loi et sauvegarde des libertés des citoyens et de l'ordre social, sans aucune référence à la figure impériale. Il ne s'agit pas tant de rendre l'Armorique à l'autorité d'Honorius que de rendre à l'Armorique un statut digne d'une province romaine. Dans l'évocation d'Albinus, son successeur au poste de préfet de la Ville, le poète reprend cette forme d'autonomisation de la représentation du pouvoir par rapport à la figure princière en indiquant que c'est Rome qui a choisi son préfet, et non le prince $(1,467-469)$ :

namque meus, quem Roma meo subiunxit honore

«mon cher Albinus en effet, lui que Rome fit mon successeur en mes fonctions » (trad. É. Wolff).

Tout se passe ici comme si la Ville s'était donné son propre préfet, évidemment choisi « au mérite ", sans l'avoir reçu d'une nomination princière. Dans tous ces personnages, nous retrouvons, distillée comme dans la figure de Constance, une vision certes « chiaramente politica, di tendenze nettamente conservatrici-aristocratiche, legata alla norme dei boni uiri e all'ideale della ciuilitas ${ }^{121} "$, mais qui surtout efface la figure princière au profit des « grands serviteurs de l'État » en qui survit toute la morale des uiri ciuiles.

Or cet amour des vertus civiles semble difficilement pouvoir s'exercer dans le centre même du pouvoir, à la cour. Lucillus en est le parfait exemple, lui qui a su rester probe dans une cour de perdition, ce qui lui vaut (avec un jeu de mots évident sur son nom) de rejoindre les antiques pourfendeurs des vices, les satiristes Lucilius, Juvénal et Turnus, ardents défenseurs du mos maiorum (1, 607-614) :

Non olim sacri iustissimus arbiter auri Circumsistentes reppulit Harpyias?

Harpyias, quarum discerpitur unguibus orbis, Quae pede glutineo quod tetigere trahunt,

Quae luscum faciunt Argum, quae Lyncea caecum, Inter custodes publica furta uolant;

Sed non Lucillum Briareia praeda fefellit, Totque simul manibus restitit una manus.

« N’a-t-il pas jadis, quand il disposait avec tant d'équité du trésor sacré, repoussé les Harpies qui se dressaient tout autour de lui ? ces Harpies qui de leurs griffes déchirent l'univers, qui de leurs pattes engluées entraînent tout ce qu'elles ont touché, qui rendent borgne Argus et Lyncée aveugle: au milieu des gardiens s'envolent les biens publics dérobés. Mais à Lucillus n'a pas échappé ce brigandage digne de Briarée et à tant de mains liguées résista la main d'un seul » (trad. É. Wolff).

91 Face à une corruption généralisée, dont on notera qu'elle recoupe ce que Claudien soulignait dans le Contre Rufin et le Contre Eutrope, mais... pour l'Orient ${ }^{122}$, Lucillus choisit de lutter avec l'ardeur des anciens censeurs (1, 605: censoria lima). Mais d'autres préfèrent des responsabilités éloignées de la cour, où s'expriment plus librement leurs qualités civiles, comme Lachanius, le père du poète, qui a exercé des fonctions auliques mais leur préfère l'administration de sa région d'Italie dont on dit constantem sibi pariterque mitem fuisse $(1,389)$, «qu'il s'y montra à la fois ferme et bienveillant»), ou encore Victorinus, ancien gouverneur de Bretagne, où il n'a laissé que le souvenir de ses vertus $(1,507-509)$ : 
illustris nuper sacrae comes additus aulae contempsit summos ruris amore gradus

« attaché naguère à la cour sacrée comme illustre comte, il a dédaigné par amour

des champs ce rang suprême » (trad. É. Wolff)

réactivant ainsi les vertus des antiques Cincinnatus, Serranus ou Fabricius, comme le poète le dira plus tard pour Protadius $(1,557-558)$.

Tout cet ensemble mérite d'être mis en regard des analyses que nous menions sur la figure du prince et qui ici éclairent deux aspects à notre sens fondamentaux de l'impossibilité de faire naître autour de la figure d'Honorius une forme de consensus qui réunirait chrétiens et païens, romains traditionnels et nouvelles élites auliques.

Le premier aspect est l'exaltation de la périphérie au détriment du centre, qui ne doit évidemment pas être mise en contradiction avec l'exaltation de Rome. Car si Rome a été condamnée par les princes à n'être plus que la périphérie du pouvoir, c'est de cette périphérie (et non de la cour) qu'émanent en réalité les valeurs véritables qui construisent l'Empire. Or Rutilius écrit précisément à un moment où le centre supposé du pouvoir (Ravenne, résidence de la cour) peine à rétablir son autorité sur les zones périphériques, ce qui évidemment invite à lire ses déclarations comme le reflet d'une "crise de confiance» des élites provinciales dans la capacité du supposé centre politique à assurer la survie de leur mode de vie et de leurs structures sociales. Mais un autre élément est à prendre en compte dans cette représentation à la fois «provinciale» et «urbocentrique» de la romanité, c'est la pérennité de l'administration romaine, sa capacité à vivre en quelque sorte "en autarcie » par rapport au pouvoir central, à continuer tant bien que mal à fonctionner même coupée de la cour. Si l'on remet en perspective avec les tentatives de reconfiguration de la figure princière l'idéal politique de Rutilius tel que résumé de façon juste par $\mathrm{L}$. Alfonsi (1955, p. 129) comme " amministrazione in mano ai uiri boni, ai rectores boni; legame di riconoscenza ai publici poteri; conservazione dei prisci mores ", la valeur de propagande que cet auteur donnait au De reditu suo apparaît sous un éclairage nouveau. Pour toute une partie de l'aristocratie romaine, la figure impériale, parce qu'elle demeure liée, malgré les efforts de reconfiguration, à un mode d'exercice du pouvoir dont elle réprouve la collusion idéologique avec le christianisme, mais aussi la corruption et l'inefficacité, devient une sorte d'horizon lointain, étranger à la véritable romanité qui se construit et se conserve ailleurs dans la réactivation du lien du populus Romanus avec les valeurs que porte l'ancienne capitale. Sans doute est-ce un signe (inquiétant pour l'autorité impériale en Occident) que l'Empire n'est pas incarné dans la figure de l'empereur, mais que la figure impériale est tout au mieux un symbole de l'universalité de l'Empire.

L'ensemble des analyses précédentes nous conduit à quelques remarques en guise de conclusion de notre réflexion sans doute encore très partielle sur le modelage princier et les résistances à ces constructions idéologiques au début du v viècle.

L'opposition entre une vision orientale et une vision occidentale du pouvoir impérial apparaît comme en partie un topos, en partie un parti-pris idéologique et en partie une réalité. C'est un topos car Claudien suit Pacatus et toute une tradition romaine sur le thème de l'Orient corrupteur des gouvernants et siège de toutes les tyrannies et de 
l'arbitraire de monarques fainéants. C'est aussi un parti-pris idéologique car ce thème est utilisé à un moment où les relations entre Orient et Occident sont mauvaises, mais également où la jeunesse du prince occidental impose qu'on le légitime d'une manière ou d'une autre comme un prince romain en devenir qui sait s'affranchir de la tentation d'une corruption orientalisante. C'est enfin une réalité, mais sur un mode surprenant, qui est celui non de l'opposition entre un dominat qui s'exercerait en Orient et une forme (rénovée et largement illusoire) de principat que l'on voudrait faire admettre comme le renouveau de l'Empire d'Occident, mais celui de l'opposition entre d'une part un modèle monarchique aulique et chrétien et de l'autre un modèle civique, romain et traditionnel. La tension entre ces deux modèles princiers, nettement visible chez Claudien qui gomme à dessein l'aspect religieux, signe qu'il est problématique, fait qu'ils se superposent dans un discours fluctuant sur le prince, dont chaque groupe social essaie de tirer la figure vers ce qui lui paraît le plus propre à exalter l'idée qu'il se fait du gouvernement impérial. Toutefois, cette tension ne crée pas chez Claudien de relativisme, au sens où tous les discours sur le prince se vaudraient et pourraient se superposer à l'infini et sans modèle dominant. Il se crée au contraire en Occident un discours sur le prince dont la cohérence est frappante, et où la superposition des deux dimensions monarchique et civique est l'objet d'une négociation subtile menée par les propagandistes (Claudien en particulier, mais aussi l'entourage chrétien du prince) à partir du modèle de Théodose.

La réactivation autour d'Honorius des vertus de l'optimus princeps n'est donc pas, elle non plus, seulement de la topique politico-littéraire, mais c'est bien un thème qui constitue la figure princière dans un contexte précis, où l'on insiste sur un renouvellement de la pratique du pouvoir initié par Théodose et où Honorius doit prendre sa place. Le passage du prince-enfant du Panégyrique sur le quatrième consulat d'Honorius au prince adulte et régnant du Panégyrique sur le sixième consulat et l'insistance sur la dimension initiatique (au sens religieux du terme) de la venue d'Honorius à Rome comme rite d'assomption du pouvoir réel confirment cette idée et réaffirment la part essentielle de la Ville dans la construction du modèle impérial. Ce faisant, ce modelage traditionnel et romain trouve aussi sa limite, car la superposition des deux visions du prince, monarque et citoyen, tentée par le Panégyrique sur le sixième consulat d'Honorius pose le problème de la réactivation des données cultuelles qui manifestent, dans l'espace sacré de Rome, le lien qui existe entre la Fortune du prince, celle de la Ville et celle de l'État. Or, si cette logique est poussée à son achèvement, elle aboutit, comme le montre l'itinerarium symbolique d'Honorius reconstruit par Claudien, à faire droit, au moins dans les actes, sinon dans la conviction, à toute une tradition cultuelle qui est étrangère à la religion du prince et d'une partie influente de son entourage.

C'est cette tension visible avec le modèle chrétien qui donne l'impression que Claudien ne lit que le versant civique d'une réalité bien plus complexe, et non un mépris du poète pour une religion qu'il ne partage pas ou quelque autre raison de circonstance. Parce qu'il tient à rétablir le lien civique entre le prince et la Ville que met en un sens à mal le lien religieux chrétien, qui rapproche l'image de Rome de celle de Constantinople et le christianissimus princeps du basileus qui gouverne l'Orient et pour lequel la composante chrétienne du pouvoir est essentielle, Claudien prend le risque de dissocier la personne du prince (chrétien) de sa fonction et de poser la primauté de cette dernière sur la première. Mais la prise en compte de l'ensemble du dossier de l' adventus de 404 impose paradoxalement à nos yeux de modernes la nécessité de sortir 
d'une forme de représentation schizophrénique du prince qui poserait avec conviction certains actes (aller prier sur la tombe de Pierre) et d'autres sans conviction (faire semblant d'honorer l'espace sacré de Rome) pour bien voir au contraire qu'il s'agit, quelle que soit la réalité, d'un modelage idéologique qui tend à concilier des éléments politiquement inconciliables. Un empereur romain ne peut pas être chrétien, car la dimension sacrée et cultuelle de la fonction, telle qu'elle est consubstantiellement liée à l'exercice du pouvoir dans le principat, est incompatible avec l'exigence du christianisme qui ne tolère aucune autre pratique que la sienne. Le remodelage idéologique d'un prince à la fois totalement romain et totalement chrétien, tenté pour des raisons sans doute à la fois d'intérêts politiques immédiats et de vision à long terme, se heurte à ce premier écueil, tout en en révélant un second, encore plus grave peut-être, qui est précisément que ce prince-là se prête au remodelage tant sa personnalité propre (qu'il pourrait légitimement exprimer en 404, ce qu'il fait d'ailleurs peut-être en partie) est effacée et sa ligne politique, si elle existe, peu claire.

Or c'est exactement ce que Rutilius souligne en se fondant, une décennie plus tard, sur l'« épreuve des faits » dont on sait qu'elle est, dans la construction idéologique, à la fois un outil commode de persuasion et une notion assez floue pour se plier aisément à dire une chose et son contraire. Comme « les faits parlent d'eux-mêmes » dans la bouche de l'idéologue et disent évidemment exactement ce qu'il veut faire entendre, Rutilius peut feindre de ne parler que de "petites choses » - tel ami qu'il a croisé, tel autre dont il apprend des nouvelles - pour dire en réalité l'échec de la tentative de faire accepter aux élites sénatoriales et provinciales un portrait d'Honorius (enfermé de nouveau à Ravenne et décidément chrétien) en nouveau Trajan. Si le prince ne pouvait, au moment où il cherchait à se légitimer, se passer de Rome, la romanité peut très bien se passer d'Honorius, et les noces de la Ville et de son prince, annoncées par le Panégyrique sur le sixième consulat d'Honorius, ne sont en réalité, en raison de la personnalité de ce prince et du mode de gouvernement qu'il a adopté, que des noces de papier.

Du modelage du prince en nouveau Trajan on est passé à une forme particulièrement frappante d'opposition à Honorius, l'oblitération pure et simple de la figure princière, réduite au rôle qu'Honorius joue aux yeux de Rutilius dans le processus de défense de la romanité : aucun. La capitale, délaissée par ce prince inutile, remplace désormais cette figure si peu romaine par une forme de rayonnement par capillarité. Dans les vrais Romains que côtoie Rutilius, s'achève la reconfiguration d'une figure d'Empire sans empereur, où l'empire de Rome sur le monde passe par ses serviteurs les plus dignes et non par la figure, lointaine, fantomatique et quasi absente, d'un prince qui n'incarne plus au mieux qu'un vague symbole du pouvoir, au pire que la réussite d'un clan qui ne comprend plus les véritables valeurs romaines et qui les trahit. Dans cette partition que propose Rutilius, il faudrait d'ailleurs bien se garder de reproduire artificiellement les clivages païen/chrétien, cour/provinces, car l'éloge de Constance, homme de cour et chrétien, ne se comprendrait pas. Ce ne sont donc pas tant des résistances religieuses ou sociales qui sont sous-jacentes aux prises de position de Rutilius que le constat de faillite d'une forme particulière d'exercice du pouvoir impérial. 


\section{BIBLIOGRAPHIE}

ALFONSI L. 1955, « Significato politico e valore poetico nel De reditu suo di Rutilio Namaziano », StudRom 3, p. 125-139.

BLECKMANN B. 1997, « Honorius und das Ende der römischen Herrschaft in Westeuropa », HZ 265, 1, p. 561-595.

BORN L. K. 1934, « The Perfect Prince According to the Latin Panegyrist », AJPh 55, 1, p. 20-35. BRUGGISSER P. 2011, « Rutilius Namatianus et le génie du sénat de Rome : le verdict d'une inscription de la ville de Rome (CIL VI 41378) », Hermes 139, 4, p. 494-500.

BUREAU B. 2010, «Identités brouillées, une réflexion sur l'appartenance romaine au début du v siècle à partir d'un problème textuel (Rutilius Namatianus, Red. 1, 213-216 et Querolus 30) », in $\mathrm{M}$. BANDENET, C. CHILLET, C. COURRIER (dir.), Figures de l'identité. Naissance et destin des modèles communautaires dans le monde romain, Sociétés, espaces, temps, ENS Éd., p. 303-323.

- 2014, «Idealised Past and Contested Tradition: Claudian's Panegyric for the Sixth Consulship of Honorius and Prudentius' Contra Symmachum ", in B. ALROTH, C. SCHEFFER (ed.), Attitudes towards the Past in Antiquity. Creating Identities. Proceedings of an International Conference Held at Stockholm University, 15-17 May 2009, Stockholm Studies in Classical Archaeology 14, Stockholm, Stockholm University, p. 301-310.

FUHRMANN M. 1968, « Die Romidee der Spätantike », HZ 207, 1, p. 529-561.

GUIPPONI-GINESTE M.-F. 2007, « Le retour du prince à Rome : voyage initiatique entre parcours réel, symbolique et textuel dans le Panégyrique pour le VI $I^{\text {èe }}$ consulat d'Honorius de Claudien ", Camenae 2, 2007 [en ligne]. URL : http://www.paris-sorbonne.fr/IMG/pdf/MF_Gineste.pdf.

HAGL W. 1997, Arcadius Apis imperator. Synesios von Kyrene und sein Beitrag zum Herrscherideal der Spätantike, Frankfurter althistorische Beiträge 1, Stuttgart, F. Steiner.

HEIM F. 1999, CR de Hagl 1997, Latomus 58/3, p. 694-696.

INGLEBERT H. 1996, « "L'histoire de Rome" dans l'Antiquité tardive : un concept équivoque », Latomus 55/3, p. 544-567.

LACOMBRADE C. 1951, Le discours sur la royauté de Synésios de Cyrène à l'empereur Arcadios, Paris, Les Belles Lettres.

LIPPOLD A. 1968, « Herrscherideal und Traditionsverbundenheit im Panegyricus des Pacatus ». Historia 17, 2, p. 228-250.

MACCORMACK S. 1972, "Change and Continuity in Late Antiquity: The Ceremony of "Adventus" ", Historia 21, 4, p. 721-752.

- 1975, «Roma, Constantinopolis, the Emperor, and His Genius », CQ 25, 1, p. 131-150.

MCEVoY M. 2010, « Rome and the Transformation of the Imperial Office in the Late Fourth-MidFifth Centuries AD », PBSR 78, p. 151-192.

MATHISEN R.W. 1984, « Emigrants, Exiles, and Survivors: Aristocratic Options in Visigothic Aquitania », Phoenix 38, 2, p. 159-170.

PASCHOUD F. 1967, Roma aeterna. Études sur le patriotisme romain dans l'Occident latin à l'époque des grandes invasions. Bibliotheca Helvetica Romana 7, Rome, Institut suisse de Rome. 
PIETSCH C. 2001, « Aeternas temptare vias: zur Romidee im Werk des Prudentius », Hermes 129, 2,

p. 259-275.

RATTI S. 2005, « Le De reditu suo de Rutilius Namatianus : un hymne païen à la vie », VL 173, 1, p. $75-86$.

ROBERTS M. 2001, « Rome Personified, Rome Epitomized: Representations of Rome in the Poetry of the Early Fifth Century », AJPh 122, 4, p. 533-565.

WALlACE-HADRILl A. 1982, «Civilis Princeps: Between Citizen and King », JRS 72, p. 32-48.

WARE C. 2012, Claudian and the Roman Epic Tradition, Cambridge, Cambridge University Press.

ZARINI V. 1999, « Histoire, panégyrique et poésie : trois éloges de Rome autour de l'an 400

(Ammien Marcellin, Claudien, Rutilius Namatianus) », Ktema 24, p. 167-179.

\section{NOTES}

1. Considérer par ex. que l'interdiction progressive des cultes traditionnels marque le passage du christianisme du statut de religion des princes à celui de religion d'État est, comme on le sait bien et comme nous l'éclairerons dans la suite de cet article, extrêmement réducteur, dans la mesure où la période voit encore cohabiter des manifestations religieuses traditionnelles et des cérémonies chrétiennes, et où l'interdiction se heurte sans doute, en un temps aussi troublé, au souci de trouver dans les forces divines le plus d'appui possible.

2. Pour une approche intéressante et nouvelle de la question même de la «poésie politique » dans le cas de Claudien, voir WARE 2012.

3. Sur la figure de Rome, voir ZARINI 1999, ROBERTS 2001 et, avant eux, PASCHOUD 1967.

4. La question du statut du poème de Rutilius est très complexe, voir par ex. ALFONSI 1955. Le destinataire du poème, nommé seulement lector au premier distique (1, 1-2 : uelocem potius reditum mirabere, lector, / tam cito Romuleis posse carere bonis), n'est pas aisé à reconstruire. Les propos extrêmement virulents du poète contre les moines et contre certains hauts fonctionnaires romains pourraient laisser supposer une audience réduite à un cercle d'amis partageant ses opinions politiques, mais ce n'est pas absolument certain. Par ex., les moines sont l'objet de méfiance et de sarcasmes même dans certains milieux chrétiens, et les fonctionnaires auxquels s'en prend le poète sont morts ou ont été punis par le pouvoir impérial. On peut donc avoir une forme de discours politique subversif en trompe-l'œil, où la subversion ne serait pas tant dans la critique ouverte (et souvent inoffensive, Rutilius s'appliquant probablement l'utile précaution prise par Juvénal, 1, 170-171 : experiar quid concedatur in illos / quorum Flaminia tegitur cinis atque Latina) que dans les valeurs que défend le poète et dont le caractère traditionnel et romain sert de protection à un discours nettement plus critique sur le pouvoir.

5. MCEVOY 2010, p. 151-152.

6. MCEVOY 2010, p. 152.

7. On situe généralement la mort de Claudien peu après 404 : on ne possède aucune œuvre de lui qui puisse être datée au-delà de cette date et l'on perd alors totalement sa trace. S'il n'est pas mort peu après 404 , il a cessé toute activité poétique, au point que l'on a pu penser qu'il avait été disgracié, ce que rien n'autorise à croire. Tout au 
contraire, le fait que Stilicon soit probablement à l'origine de la publication des poèmes politiques laisse penser que le poète est mort au sommet de sa gloire et de son influence politique.

8. MCEVOY 2010, p. 153.

9. ROBERTS 2001, p. 551, posait à propos du poème de Rutilius cette question essentielle : « Is the de reditu suo a celebration of Rome's continuing greatness or an elegy for an era that is passing? » Une partie de notre propos consistera précisément à définir ce qu'il faut lire dans la notion de "continuing greatness » et ce que, sur les mêmes thèmes ouvertement politiques, l'élégie (sensible ailleurs) peut laisser à la satire, au sens romain et moral du terme.

10. Sans anticiper sur ce que nous verrons ci-dessous, l'édition de deux nouveaux fragments du livre 2 du De reditu par V. Tandoi en 1975, dont l'un contient un éloge appuyé de Constance (le futur Constance III), ne doit pas nous tromper. À lire le fragment à la lumière de l'élévation à la pourpre de Constance en 421 , on masquerait le fait que le Constance dont Rutilius semble goûter particulièrement la politique n'est encore qu'un général et patrice, et non un prince impérial.

11. Rappelons pour mémoire que le jeune Honorius n'a guère eu le temps d'apprendre paisiblement son métier de souverain. Dès la troisième année de son règne (397), le comte d'Afrique, Gildon, refusa de se soumettre à lui au profit de la pars orientalis gouvernée par le fils aîné de Théodose, Arcadius. Une extrême tension diplomatique entre l'Orient et l'Occident aboutit en 397 à ce que le régent d'Honorius, Stilicon, soit déclaré hostis publicus en Orient. Lorsque l'animosité entre les deux parties de l'Empire se calme un peu (vers 400), c'est Alaric qui empoisonne le règne par son incursion en Italie, laquelle conduit aux deux batailles de Pollentia et Vérone (402) qui éloignent le danger sans l'anéantir. Le triomphe de 404 sur les Goths est de courte durée puisqu'en 406 Stilicon doit combattre Radagaise et les Ostrogoths avant que, le 31 décembre 406, la frontière rhénane ne cède devant les populations germaniques. Toute la suite du règne d'Honorius est troublée par de graves difficultés militaires, de multiples usurpations et une instabilité croissante de l'Occident, marquée profondément par la prise de Rome et son pillage par Alaric en 410.

12. WALLACE-HADRILL 1982 opère une très intéressante synthèse entre les deux points de vue que nous énonçons ici et montre, à notre sens de manière décisive, que l'image du prince telle que la percevaient les Romains reposait sur un va-et-vient constant entre les deux pôles que la recherche moderne a parfois eu tendance à considérer comme exclusifs l'un de l'autre. On verra plus loin que cela est encore plus vrai peut-être du règne qui nous occupe.

13. Par ex. l'utilisation par Auguste et ses successeurs de la tribunicia potestas qui repose clairement (sans s'identifier à lui) sur le cadre légal défini pour le pouvoir des tribuns de la plèbe.

14. Qu'il puisse s'agir d'une volonté de s'autoreprésenter en princeps-ciuis plus que d'une réactivation réelle des limites constitutionnelles que le prince recevrait de la source de son pouvoir, l'iconographie le montre bien: «the iconography of the principate emphasises the emperor's 'republican' status: his titulature draws attention to the legal formalities, while the often bare-headed image bespeaks the 'simple citizen'. Contrast the overladen imagery of the dominate » (WALLACE-HADRILL 1982, p. 32).

15. WALLACE-HADRILL 1982, p. 32. 


\section{INGLEBERT 1996.}

17. INGLEBERT 1996, p. 548.

18. INGLEBERT 1996, p. 550.

19. Inglebert 1996, p. 553.

20. INGLEBERT 1996, p. 555.

21. INGLEBERT 1996, p. 566.

22. Éclairante, mais discutable sur plus d'un point, est à ce sujet la conclusion de ROBERTS 2001, p. 563 : " how were Rome and its traditions to be viewed now that Christianity was triumphant? [...] Rome - at least the image of Rome- was resilient; long established patterns of thought did not easily change with an individual's change in religious status. But the process of secularization [...] defined the terms of the debate for a century or more ». On peut en particulier s'interroger ici sur le concept de résilience de l'image de Rome, au moins pour le début du règne d'Honorius. S'il y a résilience, nous le verrons, elle peut aussi se lire, pensons-nous, sous la forme plus active et volontariste d'une restauration.

23. Sauf mention contraire, les traductions sont celles de l'auteur.

24. En déclarant Stilicon hostis publicus, en réponse à l'intervention du régent en Orient, la pars orientalis a en quelque sorte institutionnalisé les rapports tendus entre les deux partes depuis que Stilicon a proclamé qu'il avait été établi régent sur les deux frères, et non sur le seul Honorius, et s'est ainsi arrogé le droit d'intervenir dans les affaires d'Orient.

25. Sans doute est-ce ainsi qu'il faut comprendre l'allusion au gouvernement par une femme, qui vise probablement Sémiramis, la fondatrice plus ou moins légendaire de Babylone, mais peut rappeler, plus près de Claudien, Zénobie qui, si elle ne régnait pas vraiment sur l'Assyrie, tenta de s'imposer face à l'empereur Aurélien qui la captura pendant l'expédition de 272.

26. Ce texte pose en particulier (voir LIPPOLD 1968, p. 237, n. 60) la question de savoir si Théodose a pensé ou non à rétablir la censure, en lien avec le discours (perdu) de Symmaque De censura non restituenda (Symmaque, Ep. 4, 29 et 5, 9), mais cette question disputée est un peu accessoire ici, face à la tonalité « républicaine » générale.

27. On notera le mot regnum qui souligne combien ce n'est pas la forme du gouvernement monarchique qui est ici remise en question, mais plutôt la manière de l'exercer, en souverain-citoyen ou en despote.

28. Le mot se trouve dans le panégyrique aux v. 47,352 et 378 , mais dans un contexte tout différent, sur lequel nous reviendrons.

29. Quoi qu'il en soit du rétablissement de la censure, Théodose s'est appliqué à luimême, pour les appliquer ensuite aux autres, les exigences qui, constitutionnellement, revenaient autrefois aux censeurs. Depuis Domitien, qui s'était octroyé en 84 la censure perpétuelle, les princes exerçaient la puissance censoriale sur le modèle de la tribunicia potestas. Dans un passage probablement fictif de l'Histoire Auguste, Dèce imagine de rétablir la censure pour son frère Valérien, ce que fera effectivement épisodiquement Constantin.

30. Signe probable que la question de la censure en tant que telle ne se pose absolument plus. 
31. Ce thème est constant dans le discours que Théodose adresse à son fils. Il serait trop long de détailler ici ces éléments, mais il est clair en particulier que Claudien relit pour Honorius les maximes de bon gouvernement du De clementia de Sénèque. Voir cidessous.

32. MCEVOY 2010, p. 175, fait à ce sujet une remarque particulièrement pertinente : «modern historians writing of the regimes of both Honorius and Valentinian III have tended to forget that both of these were largely eastern regimes that had been imposed upon the west. Honorius was the son of an eastern emperor, and originally had been made Augustus at Constantinople in 393. »

33. Né le 9 septembre 384, Honorius a 13 ans lorsqu'il reçoit ce discours, c'est donc un adulescens dont la formation n'est pas, aux yeux d'un Romain, absolument complète. Son frère Arcadius, qui a 20 ans, est logiquement responsable de ses actes, ce qui pourrait expliquer que Théodose ne s'adresse pas à lui, mais ce fait est évidemment utilisé par Claudien pour souligner qu'en un sens il est trop tard pour remodeler le très oriental héritier de Théodose, jouet de ses ministres, et qui est ainsi montré, implicitement, comme trahissant l'idéal de son père. Claudien ne peut évidemment rien dire de tel explicitement, mais tout l'art du panégyrique consiste précisément en ce jeu subtil qui devait ravir les auditeurs occidentaux et rendre furieux les orientaux, sans qu'ils puissent protester puisque rien ne leur donne prise.

34. Le précédent généralement invoqué est celui de Gratien, mais il a 16 ans à la mort de son père.

35. MCEVOY 2010, p. 154.

36. " It did mean that alongside the soldier-emperor model, there was now a new and acceptable exemplar of a more predominantly ceremonial model of imperial rule, as a role that could in fact be fulfilled by a child or an adult" (MCEvoY 2010, p. 169). Toutefois, cet auteur justifie l'inactivité apparente d'Honorius devenu adulte par la pérennisation de ce modèle, ce qui n'est pas en tout cas ce que Claudien et Stilicon disent attendre de lui dans ces années. Il faut donc, comme nous le verrons, nuancer cette idée, au moins du point de vue du discours (MCEVoY 2010, p. 168) : « What might be called an 'infantilization' of the imperial office had taken place -a process whereby child-emperors who reached adulthood in the imperial office continued to be presented essentially as minors, whose predominant function lay in their ceremonial and religious role, while the more active imperial function of military leadership, in particular, was delegated to a single dominant general. This need not mean that a child-turned-adult emperor might never exercise active imperial functions, such as judicial responsibilities, nor did it mean that each child-emperor court that was established across this period functioned in precisely the same way. But it did mean that ceremonial or child-emperor rule came to be viewed as a 'norm' of the late Roman political system, and this had inevitable implications for the function and perception of the imperial office during this period.»

37. Ici évidemment on voit fonctionner la double articulation du panégyrique: d'un côté on dit au prince, en y mettant toutes les formes, qu'il doit travailler à se conformer à l'image de l'optimus princeps, et de l'autre on dit aux sujets qu'ils ne peuvent demander à leur jeune prince d'être immédiatement Théodose ou Trajan.

38. Sur cette entrée à Milan, voir MACCORMACK 1972, p. 737-738: «the allusion is to an Egyptian festival celebrated at the winter solstice, when the statue of a small boy 
representing the sun at its lowest point, when the days are beginning to get longer, was carried from a shrine. It is interesting that this simile of Claudian's likens the emperor to a symbol for the sun -it is a remnant of the old imagery. » Quelle est cette " old imagery »? Est-ce celle de l'Égypte, ici importée pour glorifier le jeune prince, ou celle de Sol inuictus, la divinité tutélaire des princes antérieurs à Constantin et de Constantin lui-même avant sa conversion, réactivée ici dans un protocole dont le caractère pourrait alors renvoyer, dans une sorte de saut dynastique, en deçà de Constantin ?

39. On peut d'ailleurs supposer que certains courtisans avaient entendu la charge de Pacatus contre l'Orient moins de dix ans plus tôt. Pour leurs oreilles, les mots d'un poète, égyptien qui plus est, devaient sonner étrangement.

40. Ici se pose évidemment la question de l'unité de l'Empire, à laquelle Claudien et ses mécènes semblent suffisamment attachés pour ne jamais, même aux moments de plus grande tension, critiquer directement Arcadius, qui est toujours présent " en creux » mais jamais visé.

41. Sur ce texte et son interprétation politique, voir HAGL 1997 avec HEIM 1999, même si la proximité entre les deux discours, celui de Synésius et celui de Claudien, est selon nous en trompe-l'œil.

42. WALLACE-HADRILL 1982, p. 33, voit une première manifestation de cette topique dans Xénophon, Cyr. 8, 3, 1-23, et 8, 1, 40, et le faste avec lequel Cyrus paraît pour la première

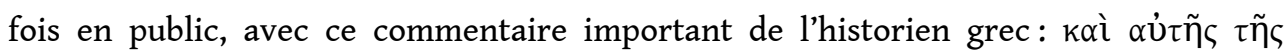

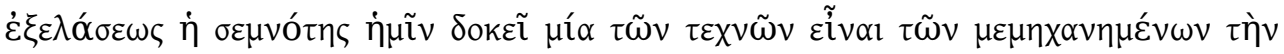

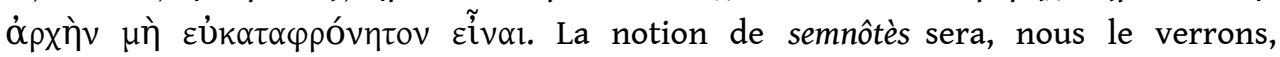
particulièrement importante dans la suite.

43. Sur ce texte, voir LACOMBRADE 1951.

44. Le rapprochement est fait par WALLACE-HADRILL 1982, p. 33, mais il relie, à tort selon nous, ce texte et Ammien qui s'était moqué du décorum de Constance II dans le célèbre passage de son entrée à Rome $(16,10)$. Les deux textes ne visent pas du tout le même comportement. Ce qu'Ammien reproche à Constance, c'est d'entrer en conquérant dans la Ville qui est la souveraine de l'univers et d'y donner le spectacle de sa puissance militaire. Ce que pointe Synésius, c'est l'oisiveté et le luxe d'un prince qui vit enfermé dans son palais à s'occuper de loisirs indignes de sa fonction.

45. Voir WALLACE-HADRILL 1982, p. 41. Le terme grec désigne l'aura de dignité et de majesté qui se dégage d'un individu et le place au-dessus des mortels. Le mot s'applique en effet d'abord à des divinités, et c'est par reflet de la "gloire » ou de la "majesté » divine qu'il s'applique au roi.

46. 4 Honor. 121-123: Hoc nobilis ortu / Nasceris aequaeua cum maiestate creatus / Nullaque priuatae passus contagia sortis.

47. Synésius ne dit d'ailleurs pas autre chose à Arcadius, puisque le chapitre qui précède celui que nous avons cité traite de l'importance pour un prince de s'illustrer personnellement à la guerre et auprès des soldats.

48. Cet élément est d'autant plus important qu'il ne semble guère y avoir eu de contestation lors de l'accession au trône d'Honorius. Tout est bien ici une question de négociation idéologique et de construction d'une propagande qui s'appuie sur les représentations que l'on se fait du pouvoir impérial dans le monde romain : le modèle aulique, souvent décrié comme une dérive du pouvoir, ne montre aucun affaiblissement de l'institution (personne ne songe à remettre en question l'autorité impériale), mais 
plutôt une modification du statut du prince «creating a new, but very strong and enduring, model of fer more civilian or ceremonial-style emperorship than had existed previously " (MCEVOY 2010, p. 158).

49. Nous croisons ici un débat important chez les historiens du principat, celui de l'articulation des deux éléments et de leur présence dès l'origine dans la perception que les Romains ont du prince. WALLACE-HADRILL 1982, p. 36, rappelle une position défendue entre autres par Alföldi et qui définit la part cérémonielle et religieuse du principat comme première : "for Alföldi the religious ceremonial represents the essence of Roman monarchy, while the republican element, the conduct of the princeps as a simple citizen, is a subordinate modification. Only a minute fraction of the population, the senate, cared about that sort of thing. " Il souligne ainsi ce que cette position peut avoir d'opposé à celle qui tient le principat comme l'évolution d'une ou plusieurs magistratures républicaines sans rupture «institutionnelle». Nous nous garderons bien de prendre parti dans un débat qui ne concerne pas notre période, mais nous le signalons car il éclaire les modalités de modelage de la figure princière, figure non sacrale ou civique, mais sacrale et civique.

50. MCEVOY 2010, p. 176.

51. Nous ne dirons rien ici, faute d'avoir chez Claudien une attestation certaine de cette idée, du fait que, si Honorius est encore à l'âge où l'on peut et doit être conseillé, Arcadius, lui, est un prince tout à fait responsable de ses choix, et en ce sens la position de Claudien/Théodose et celle de Synésius sont différentes. Le poète met en scène l'éducation d'un prince qui montre (selon lui évidemment) les plus remarquables dispositions, le philosophe de Cyrène entreprend de corriger les dérives des premières années d'Arcadius. On notera que, concordia Augustorum oblige, ici encore jamais Claudien ne critique explicitement Arcadius. Soit son discours est vague («l'Orient», " des gens ", « on »...), soit il est précis mais se déchaîne contre les mauvais conseillers du prince (Rufin, Eutrope), en épargnant celui-ci dont l'absence (et donc l'inaction) fait cependant parfois l'effet d'un silence assourdissant.

52. WALLACE-HADRILL 1982, p. 45.

53. On pourrait préciser avec l'entourage de Rutilius qui sont ces auditeurs attentifs au respect de la tradition : il s'agit d'une aristocratie romaine ou provinciale liée au sénat et attachée à la religion traditionnelle. Voir ci-dessous.

54. Il ne faut jamais sous-estimer le fait qu'Honorius succède à son père seulement quatre mois après la fin de la dernière usurpation, celle d'Eugène, mort le 6 septembre 394, alors que Théodose meurt le 17 janvier 395, et que la question de la légitimité du jeune prince ne pouvait pas ne pas se poser. Affirmer la continuité dynastique pouvait assurer la loyauté des fidèles de Théodose, qui avait pris grand soin d'user de clémence avec le parti d'Eugène. Mais la clémence du père ne valait pas allégeance au fils, qui devait donc donner des garanties aux anciens soutiens d'Eugène, en particulier à la partie du sénat attachée à la religion traditionnelle. Pour s'assurer le soutien de ces nobles, Eugène avait mené une politique de restauration des traditions, et c'est dans ce contexte qu'il faut lire nos panégyriques.

55. Constance vient triompher de l'usurpateur Magnence en 357, Théodose vient à Rome après sa victoire sur l'usurpateur Maxime, et Honorius après celle de Stilicon sur Alaric. On notera, dans une perspective strictement romaine, que seul Honorius 
pourrait prétendre au triomphe de Getis, puisque les deux autres n'ont remporté de victoire que dans une guerre civile.

56. MACCORMACK 1975, p. 142.

57. Peut-être est-ce une des clés de lecture de la description en partie à charge qu'Ammien (qui est contemporain de Claudien bien que plus âgé) donne de l'adventus de Constance II $(16,10)$. Venu absque nomine ex sanguine Romano triumphaturus, Constance montre qu'il n'a aucune connaissance de la tradition romaine (on ne triomphe jamais dans une guerre civile) ou qu'il la méprise. Il tente donc d'établir par la fallacieuse réactivation de traditions qu'il bafoue une relation à la Ville que tout en lui dément puisqu'il se comporte talem se tamque immobilem, qualis in provinciis suis visebatur, ostendens. Ammien peut bien alors noter que Constance se prête ensuite à une fiction de modestie, il n'est pas jusqu'à la fascination que le faste de Rome exerce sur le prince, comme le ferait une ville étrangère, qui ne participe à disqualifier la romanité de cet adventus. Pacatus montre clairement une stratégie opposée. En amplifiant les crimes commis par Maxime, il peut éventuellement justifier un triomphe, mais surtout, en montrant combien Théodose sut se comporter en ciuis dans la Ville, il souligne que le prince, bien qu'ayant longuement vécu en Orient, possède les codes traditionnels romains qu'il applique à la perfection.

58. MACCORMACK 1975, p. 142.

59. GUIPPONI-GINESTE 2007.

60. Cette formule est, nous le verrons, bien plus qu'une vignette géographique décrivant le Palatin.

61. Notre traduction reprend partiellement celle de GUIPPONI-GINESTE 2007, en la complétant.

62. Traduction reprise de GUIPPONI-GINESTE 2007.

63. 6 Honor. 612-617.

64. Il s'agit sans nul doute d'un élément bien ancré dans la mentalité romaine puisqu'on peut le rapprocher des propos du chrétien Prudence qui identifie la cité de Rome avec son peuple, et en particulier, nous y reviendrons, avec l'aristocratie sénatoriale, voir ROBERTS 2001, p. 359, et Prudence, Sym. 1, 569-572 et 2, 443-444, qui s'oppose ici très clairement à Claudien (voir ci-dessous) : Romam dico uiros quos mentem credimus urbis, / Non genium, cuius frustra simulatur imago, «je dis que Rome ce sont les hommes, qui, je crois, font l'esprit de la Ville, et non un génie dont on représente en vain l'image ». Le Contre Symmaque est antérieur au panégyrique de deux ans, mais sans doute Claudien veut-il ici répondre à cette vision « laïque » du génie de Rome chez les chrétiens.

65. Comme le dit ROBERTS 2001, p. 544, à propos de 6Honor. 615-617: «in this formulation late roman ceremony reenacts and derives its legitimacy from the foundational act of the city's origins, as authoratively formulated by Virgil ». Toutefois, ce passage nous semble moins probant que ceux que nous présentons à la suite de GUIPPONI-GINESTE 2007.

66. Voir GUIPPONI-GINESTE 2007 qui analyse de façon très complète les étapes littéraires et religieuses de ce voyage du prince au cœur des traditions.

67. Par ex., M. McEvoy (2010, p. 189) fausse sans doute la perspective en ne percevant pas la trajectoire politique qui guide le discours impérial de Claudien depuis le 
panégyrique pour le troisième consulat d'Honorius quand elle écrit : «demonstrating that imperial respectability and connection with the security of the state became all the more important when the emperor was a child, or even a child-turned-adult emperor who continued to some degree to play a ceremonial role even upon reaching adulthood, and not to make a full transition to independent rulership ». La venue à Rome sonne ici comme une invitation aux Romains à se représenter désormais l'empereur de 20 ans comme l'acteur du pouvoir. Sur la question de la place de Stilicon dans ce schéma « actif » du pouvoir impérial, voir ci-dessous.

68. Si l'on peut pour 389 accepter la vision de M. McEvoy qui écrit que «Theodosius I's presentation of the child Honorius to the Roman senate during his triumphal visit of 389 (having brought the child all the way from Constantinople specifically for the purpose) indicate that this astute emperor recognized the value of staging imperial ceremonial in an appropriately spectacular urban venue - and was perhaps even more conscious of this when the focus of that ceremonial was a child» (MCEVOY 2010, p. 169), on ne peut la transposer à l'adventus de 404, même en donnant à Stilicon le rôle de Théodose. On peut au contraire discerner, comme nous le faisons, dans l'adventus de 404 l'accomplissement de celui de 389, ce qui expliquerait d'ailleurs pourquoi Claudien, en 398 comme en 404, a conservé bien présent à l'esprit le discours de Pacatus qui lui sert en quelque sorte de fil rouge.

69. Rappelons que le panégyrique s'ouvre sur une allusion à Fortuna redux dans une sorte de fusion entre le retour victorieux du prince et le retour à Rome de la fortune des armes. Sur Fortune, voir ci-dessous.

70. Nous rejoignons ici MCEVOY 2010, p. 173, en nuançant cependant l'aspect de l'empereur-enfant: «although, [...] concern for good relations with the senate was certainly not unique to child-emperor regimes, the increased imperial presence in the city from c. 400 onwards must have changed the dynamic. While in the fourth century distinguished senators had at times travelled to the imperial court at Trier or Milan to convey senatorial goodwill or requests, the more frequent imperial visits to Rome itself in the fifth century might allow the development of a more prolonged connection, perhaps even a direct role in imperial policy." Pour nous, il s'agit plutôt de reconfigurer une forme de gouvernement qui reposerait sur la concordia entre le prince, les généraux qui commandent les armées, et le sénat.

71. Sur les particularités du discours sur le prince ou au prince en Ville, voir MACCORMACK 1972, p. 722 : « in the Roman period the fiction of the emperor as ciuis was of real importance. In making the arrangements for an aduentus both ruler and subjects had to find the right nuances: too much honour and exaltation could be an embarrassment, too little likewise. Hence official propaganda often made its points indirectly, leaving their exact interpretation open to conjecture. »

72. WALLACE-HADRILL 1982.

73. WALLACE-HADRILL 1982, p. 42.

74. WALLACE-HADRILL 1982, p. 42.

75. Il ne faut d'ailleurs pas confondre la ciuilitas (nous dirions l'affabilité) avec une vertu plus proprement monarchique et qui se trouve déjà dans les traités sur la royauté des Grecs, la sollicitude envers les pétitionnaires. Sur ce point, voir WALLACE-HADRILL 1982, p. 35. En les confondant, on pourrait aisément prêter à l'empereur-citoyen des 
comportements qui, aux yeux des Romains, relèvent bien en réalité de sa fonction royale.

76. Il va embrasser et féliciter le nouveau consul, manifestant ainsi qu'il abolit pour un moment la différence : intueri parem accipientibus, honorem qui dabat, « [on voyait] celui qui donnait l'honneur l'égal de ceux qui le recevaient ».

77. Pline présente la chose ainsi, soulignant à la fois la vertu insigne et le caractère paradoxal de cette attitude: tu quoque inter excipientes eras, et ex ore principis ille senatorius assensus audiebatur: quodque apud principem perhibere testimonium merentibus gaudebamus, perhibebatur a principe, "toi tu étais parmi ceux qui prenaient ensuite la parole, et de la bouche d'un prince, on attendait l'assentiment d'un sénateur et le témoignage dont nous nous réjouissions qu'il soit rendu au mérite devant le prince, c'était le prince lui-même qui le portait » (Pan. Tra. 71).

78. Velut affixi curulibus suis manum tantum, et hanc cunctanter et pigre, et imputantibus similes, promerent, "comme s'ils étaient collés à leur siège ils tendaient la main seulement et encore à regret et sans empressement, et comme s'ils faisaient des reproches » (Pan. Tra. 71).

79. Il est important de noter que cette double approche de la figure princière renforce à la fois la légitimité du prince et le conservatisme social de l'élite, et donc que tout le monde y trouve son compte: «far from overturning the traditional hierarchical structure, [the change from republic to empire] reinforced it. The ceremonial ritual that cast the emperor as a citizen reflected that fact » (WALLACE-HADRILL 1982, p. 46).

80. La recusatio est topique dans la représentation du bon prince et A. Wallace-Hadrill (1982, en particulier p.36) en dégage bien la valeur quasi rituelle qui apparaît clairement dans le Panégyrique de Trajan et qui se fixe par la suite comme élément valorisant dans l'estimation d'un prince. Or, comme il le montre de manière particulièrement juste, cet acte qui marque en apparence le désir de demeurer un priuatus et de ne pas aspirer à la fonction suprême est extrêmement ambigu, car il n'a rien de traditionnel ni de républicain. Sous la République, on rivalise au contraire pour obtenir les plus hautes charges. Or ce n'est qu'au temps des imperatores qu'on voit apparaître ce thème du refus des honneurs. Ces analyses nous confortent dans l'idée que penser le prince-citoyen n'est pas lié à un discours "républicain», qui n'aurait d'ailleurs aucun sens appliqué à l'époque de Claudien, mais bien à une certaine représentation du pouvoir, ce qui explique que le thème puisse se transposer du prince lui-même à son consul, qui incarne ainsi les mêmes valeurs.

81. M. McEvoy (2010, p. 162) a une formule particulièrement juste pour définir ce que nous voyons ici à l'œuvre: "Claudian's representation of the government of young Honorius and his guardian Stilicho was essentially that of a partnership -a heavy emphasis on the youthful promise and hopeful virtues of the young emperor, coupled with the demonstrated military abilities of his general and utterly loyal guardian, Stilicho, who led the imperial armies in the field on the emperor's behalf ", mais, contrairement à ce qu'elle dit ensuite, ce partenariat n'est pas une innovation, mais bel et bien le retour à l'exercice le plus traditionnel du pouvoir impérial, puisque Tibère, par ex., qui avait largement fait ses preuves sur le champ de bataille, une fois devenu prince ne parut plus en campagne, mais y délégua des généraux.

82. L'image de Rome dans l'Antiquité tardive a été largement étudiée. Nous nous fondons ici essentiellement sur PASCHOUD 1967, FUHRMAN 1968, ROBERTS 2001 et ZARINI 1999, dont les analyses éclairent les enjeux de ce que nous observons chez Claudien puis 
chez Rutilius. Un contrepoint intéressant en contexte chrétien est fourni par PIETSCH 2001.

83. Comme le note M. Fuhrman (1968, p. 532) à propos du débat autour de Rome qui agite la société au tournant des $\mathrm{IV}^{\mathrm{e}}$ et $\mathrm{V}^{\mathrm{e}} \mathrm{s}$., « jetzt beteiligen sich Angehörige des ganzen Reiches, Heiden wie Christen, an der Debatte». Toutefois, cette conception orbocentrique du débat sur la Ville qu'il qualifie d'« ökumenische» ne doit pas être entendue comme une forme d'unanimité a minima comme il semble le croire. Pour les quelques années qui nous occupent, ce qui nous retient au contraire, ce sont les fractures profondes qui séparent les idées de Rome, même s'il est évident qu'il y a au fondement des deux représentations des strates communes de "romanité ». Nous soulignerons ici les lignes qui séparent jusqu'à les rendre presque contradictoires les deux conceptions, traditionnelle et chrétienne, de Rome, car il nous semble que c'est la difficulté, voire l'impossibilité à résoudre ces contradictions qui signent l'échec d'une reconfiguration par restauration du pouvoir impérial en Occident.

84. Sur tous ces éléments, voir FUHRMAN 1968, p. 546 sq.

85. Voir FUHRMAN 1968, p. 546 sq., et BUREAU 2014, p. 307 sq.

86. Posceret peut s'interpréter soit comme un irréel du présent, soit comme un potentiel du passé. Dans le premier cas, Claudien soulignerait, en accord avec la foi chrétienne, que ce culte a existé mais n'existe plus, dans le second, il indiquerait que cela aurait été possible dans le passé, et peut-être le serait encore.

87. FUHRMAN 1968, p. 552, cite à juste titre comme illustration de ce processus un autre passage de Claudien qui ne traite pas du prince, mais de son consul, Stil. 3, 130-173, dont nous retenons en particulier les v. 160-173, avec l'analyse de FUHRMAN 1968, p. 552-553.

88. On retiendra ici l'idée d'une « punktuelle Erneuerungsprogrammmatik » telle que la définit FUHRMAN 1968, p. 550, à propos d'Ammien Marcellin.

89. "In the light of the anti-pagan attitudes crystallized in the law of 392 , one of the great merits of Claudian's use of the Augustan vocabulary was that it was not cultic, even though it could carry conviction precisely because it fused with a past where the cultic expression of these ideas had still been possible. In short, pouring wine to one's genius or daimon was prohibited, although being learned about it was not" (MACCORMACK 1975, p. 142).

90. BRUGGISSER 2011, 497.

91. L'argumentation en faveur de Vettius Agorius Praetextatus repose sur les simples lettres VE et sur le fait que Vettius Agorius Praetextatus avait restauré le portique des Di Consentes et rendu les statues sacrosaintes. Or Capella, 1, 41, appelle le sénat des dieux les Di Consentes (BRUGGISSER 2011, p. 498).

92. BRUGGISSER 2011, p. 498.

93. V. 645-646: desuetaque cingit / Regius auratis fora fascibus Vlpia lictor, « le licteur royal aux faisceaux d'or entoure le forum de Trajan qui en a perdu l'habitude. Le temple d'Hadrien, dont parle Augustin se trouve sur le Champ de Mars »

94. MCEVOY 2010, p. 178-180.

95. Nous reprenons l'analyse de MCEVOY 2010, 185, qui nous semble particulièrement nuancée et juste. 
96. Sur le lien entre Rome et son empire universel et la mission universelle des apôtres déjà présent chez les auteurs chrétiens des II $^{\mathrm{e}}$ et III $^{\mathrm{e}}$ S., voir par ex. FUHRMAN 1968, 546.

97. MCEvoy 2010, p. 186, à partir de Prudence, Perist. 47-50.

98. "Constantinople came to be associated with the emperor, while, in due course, Rome in losing her emperor was constrained to become a lonely Roma aeterna. Before the two cities became dissociated in this manner from each other and lost their parallel roles one can identify moments of equilibrium ", note M. MACCORMACK $(1975$, p. 147), et il est probable, comme nous allons le voir, que nous sommes, avec cette lecture chrétienne de l'adventus d'Honorius en 404, dans une tentative des chrétiens de reconfigurer le lien entre pouvoir impérial et ancienne capitale.

99. Sur cet objet, voir l'analyse de MACCORMACK 1975, p. 147-148, avec les nuances que nous apportons.

100. MACCORMACK 1975, p. 148.

101. Notons que le geste indique peut-être aussi la jeunesse du prince (il a 16 ans), qui nécessite une protection particulière. La conception différente du lien avec les capitales se doublerait alors d'une représentation de la figure d'un prince en devenir par rapport à Honorius qui est bien représenté comme un adulte.

102. La légende est "entirely unique for its time, in an era when the iconography of consular diptychs remained solidly secular » (MCEVOY 2010, p. 167).

103. Si l'on considère que la parution de la version définitive du Contre Symmaque remonte bien à 402 (voir BUREAU 2014 pour un résumé des positions concernant la date de ce poème), la fracture se confirme et traduit clairement un affrontement de « conseillers » autour du jeune prince.

104. Même si nous pouvons en nuancer certains aspects, nous partageons cette constatation de MCEVOY 2010, p. 166 : «Emphasizing a certain special divine protection for a child-emperor and bringing his function as a Christian leader increasingly to the forefront of his presentation seems to have been a key to the 'selling' of child-emperor regimes in the late Roman period. It was an emphasis that specifically linked the victories of his armies to the emperor, by claiming they were a direct result of his piety, despite his absence from the battlefield... It is of tremendous significance to this presentation that this conspicuous emphasis on imperial piety above other imperial virtues continued during the adult years of these emperors who had come to the throne as children. " Il nous semble toutefois que le processus de "vente» de ce modèle princier est plus complexe et fluctuant qu'il n'y paraît ici. Stilicon semble avoir voulu "vendre " l'idée d'un empereur in progress qui aboutirait à un nouveau Trajan, mais avoir été démenti, non par une propagande inverse qui aurait défendu l'idée d'un prince ramené à un rôle de représentation de vertus, mais bel et bien par l'incapacité du prince en question à se hisser à la hauteur des espérances de son mentor. Cette lecture « déceptive » n'invalide d'ailleurs pas une lecture cynique qui verrait (en même temps que l'on affirme le pouvoir du faible prince) dans ce modelage une tentative du régent pour asseoir son propre pouvoir et ses propres ambitions.

105. Cette évidence est parfaitement bien résumée par Mcevoy 2010, p. 169: "As the territory of the western Roman empire -and thus also its revenues- shrank during this period, imperial consciousness of the symbolic importance of Rome and the need for the support of its wealthy aristocracy certainly grew. » 
106. Voir en particulier ALFoNSI 1955, p. 126, qui note «l'atmosfera [...] chiaramente politica, di tendenze nettamente conservatrici-aristocratiche, legata alla norme dei boni uiri e all'ideale della ciuilitas ».

107. Outre la mention du génie du sénat dont nous avons déjà parlé, les cultes anciens et fondateurs sont évoqués dans cette prière à Rome $(1,67-68)$, mais on voit également apparaître la puissance économique et commerciale de la ville (1,150-154), la qualité de ses infrastructures, en particulier dans l'approvisionnement en eau (1, 97-102), et évidemment la splendeur de ses monuments. De plus, quand il s'éloigne de Rome, le poète, même s'il le met sur le compte des suggestions de son amour pour la Ville, souligne le faste des spectacles et la foule qui s'y presse (1, 201-204), tous éléments qui relèvent d'une vision certes divine de Rome, mais ancrée dans des réalités vues ou vécues par le narrateur.

108. ROBERTS 2001, p. 541.

109. MACCORMACK 1975, p. 143.

110. Nous lisons ici <belli>gerum, comme la plupart des éditeurs du fragment.

111. Peut-être faut-il supposer que hiatum désigne ici la bouche largement ouverte du poète qui chante (cf. Horace, Ars 138), ce qui irait bien avec ce que l'on peut déchiffrer de la suite, mais rien n'est sûr.

112. Il est plausible de lire ici cessem (Tandoi), ce qui supposerait une négation dans ce qui précède, d'où notre traduction.

113. La destruction des livres Sibyllins a eu lieu sous Honorius et du temps où Stilicon était tout-puissant. Est-il pour autant l'instigateur de cette destruction comme l'affirme Rutilius ? Cela demeure invérifiable et peut très bien faire partie d'une assimilation du régent avec les factions chrétiennes les plus extrêmes dans le but de le discréditer encore.

114. Remarque très juste de BLECKMANN 1997, p. 563 : «bereits die heidnischen Zeitgenossen dürften dem in seiner Residenz eingeschlossenen und inaktiven jugendlichen Kaiser eine persönliche Verantwortung für die katastrophalen Zeitläufe zugewiesen haben ».

115. Dans l'idéologie honorienne, l'insistance est très clairement mise sur la souveraineté revendiquée de l'empereur sur le monde entier. Le grand mérite de BLECKMANN 1997, p. 591-592, est de montrer qu'il ne s'agit pas d'un délire de panégyriste, mais bel et bien d'un élément constitutif de la figure impériale elle-même qui se trouve temporairement démenti par les faits mais sans être jamais remis en question par la propagande impériale: "In der Regierungszeit des Honorius hatte die Diskrepanz zwischen dem auf das Ganze gerichteten Herrschaftsanspruch einerseits und den tatsächlichen Handlungsmöglichkeiten andererseits gewaltige Ausmasse erreicht. Es scheint aber, als habe man diese Diskrepanz nicht empfunden.» Avant de se hâter de parler d'aveuglement, il vaut mieux considérer que nous avons là une conséquence directe des éléments idéologiques que nous avons vus dans les parties précédentes de cet article et une profonde cohérence dans cette vision d'un Empire "à restaurer ».

116. Analyses éclairantes en ce sens de BLECKMANN 1997, dont nous tirons cette remarque importante pour notre propos (p.593): «Aber nicht nur die kaiserliche Regierung ging da von aus, dass die grosse Invasion vom Silvester 406 ein einmaliger Unfall war, der die Herrschaft Roms über die westeuropäischen Provinzen letztlich nicht ernsthaft gefährden konnte. Auch einige zuversichtliche Äusserungen 
zeitgenössischer Literaten wie Rutilius Namatianus oder Orosius zeigen, dass man am Fortbestand des Reichsverbands nicht zweifelte und die Präsenz von Germanen nur für ein vorübergehendes Unglück hielt. »

117. BLECKMANN 1997, p. 587 sq.

118. Si la diatribe contre l'or et les métaux précieux de 1, 355 sq. peut être considérée comme topique de la satire philosophique, la lutte contre la corruption menée par Lucillus $(1,605-615)$ est évoquée avec suffisamment de précision pour stigmatiser clairement les abus de la cour.

119. Voir la célèbre diatribe contre les moines $(1,439-452$ et 517-526) à propos d'un «scandale " particulier.

120. Voir RATTI 2005, BUREAU 2010.

121. ALFONSI 1955, p. 126.

122. Voir par ex. Ruf. 1, 176 sq. ou Eutr. 1, 193 sq.

\section{NOTES DE FIN}

*. Cet article est la version revue et développée d'une intervention faite à Lille dans le cadre du séminaire « Résistance au pouvoir impérial ». Je remercie les responsables de ce séminaire, et en particulier T. Benatouil et $\mathrm{S}$. Tarantino, de m'avoir fourni l'occasion de « mettre au propre» pour cette circonstance ces quelques réflexions.

\section{RÉSUMÉS}

La lecture conjointe des panégyriques pour les quatrième et sixième consulats d'Honorius de Claudien et du De reditu suo de Rutilius Namatianus montre l'existence d'un débat dans lequel la notion de romanité est confrontée à la figure singulière du prince (et de ce prince-là, Honorius). À travers le thème du lien à la ville de Rome et de la présence du prince à Rome, l'article analyse les tensions entre une vision « civique » et romaine de la fonction princière et d'autres lectures du statut de l'empereur, en lien avec la représentation chrétienne du prince et les pratiques de la cour orientale. Une décennie après Claudien, Rutilius montre l'échec, au moins dans la frange de la société qu'il représente, de cette forme de reconfiguration de la figure d'Honorius qui, prince chrétien, pourrait en même temps se donner comme le nouveau Trajan.

When we read both Claudian's panegyric for the 4th and the 6th consulship of Honorius and Rutilius Namatianus' De reditu suo, it becomes very likely that, after the death of Theodosius, there has been a debate about the exact nature and status of the principate. Considering the passages involving the city of Rome and the "civic" ideal of the principate in Claudian's poems, we try to show how Claudian and Stilicho tried to draw a renewed picture of the princeps and apply it to Honorius as a renewal of the optimus princeps according to the standards of Roman principate. But, when it is compared to both oriental discourses and practices, and Christian model of the princeps, Claudian's attempt leads to a global failure that is documented by Rutilius' ideological vision of Romanitas. As the emperor who is a devout Christian cannot completely 
assume the (partially religious) characters of the optimus princeps, the imperial model becomes in Rutilius' poetry an optional part of the general idea of Romanitas, far less important than real link to Roman culture and social organization.

\section{INDEX}

nomsmotscles Ammien Marcellin, Augustin, Capella (Martianus Mineus Felix), Cicéron, Claudien, Drepanius (Latinus Pacatus), Horace, Juvénal, Pline le Jeune, Lucilius (Caius), Prudence, Rutilius Namatianus, Sénèque, Symmaque, Synésios de Cyrène, Tite-Live, Turnus, Xénophon Mots-clés : empereur-enfant, Empire romain, Honorius, optimus princeps, panégyrique, principat, Stilicon

oeuvrecitee Histoire Auguste

Keywords : child-emperor, Roman Empire, Honorius, optimus princeps, panegyric, Principate, Stilicho

Index géographique : Armorique, Constantinople, Milan, Orient, Ravenne, Rome

\section{AUTEURS}

BRUNO BUREAU

Université Jean Moulin Lyon 3, UMR 5189 HiSoMA 